\title{
On the optimality of search matching equilibrium when workers are risk averse *
}

\author{
Etienne LEHMANN ${ }^{\dagger}$ and Bruno VAN DER LINDEN ${ }^{\ddagger}$
}

August 30, 2002

\begin{abstract}
This paper revisits the normative properties of search-matching economies when workers have concave utility functions. A general equilibrium framework is developed where agents are homogeneous and wages are bargained over. Assuming lump-sum taxation of profits, the optimal allocation of resources is characterized first when information is perfect and second when unemployed people freely choose their search effort. Compared to the first case, the optimum is characterized by imperfect unemployment insurance and lower levels of search intensity and output in the second setting. To decentralize these optima, employees should be unable to extract a rent when information is perfect. An appropriate positive rent is however needed in the second case. When the bargaining power of the workers is given, these outcomes can be implemented through a well-designed non-linear tax schedule and an appropriate level of unemployment benefits. According to the level of the bargaining power, taxation can be progressive or regressive. Negative marginal tax rates are even needed for sufficiently low levels of the bargaining power.
\end{abstract}

Keywords: Unemployment, Non-linear Taxation, Unemployment Benefits, Moral Hazard, Search, Matching.

JEL codes: J64, J65, J68, H21, D82

\footnotetext{
${ }^{*}$ This paper was written while Bruno Van der Linden was visiting EUREQua. Bruno Van der Linden thanks the French Ministère de la Recherche (EGIDE), the FNRS and Interuniversity Poles of Attraction Programmes PAI (Prime Minister's Office - Federal Office for Scientific, Technical and Cultural Affairs). We thank participants to the séminaire d'économie du travail at EUREQua, the economic seminar at the Katholieke Universiteit Leuven, the Université Catholique de Louvain, the CAM workshop on "Job search, Unemployment and the UI system" in Copenhagen, T2M 2002 and PET 2002 meetings for their comments. We thank in particular Antoine d'Autume, Pierre Cahuc, Melvin Cowles, Bruno Decreuse, Adrian Masters, Dale Mortensen, Eric Smith, Frans Spinnewyn, Etienne Wasmer and André Zylberberg.

${ }^{\dagger}$ CREUSET Université de Saint-Etienne, EUREQua Université Paris I and ERMES Université Paris 2, 12 place du Panthéon, 75005 Paris, email: elehmann@u-paris2.fr,

${ }^{\ddagger}$ FNRS and IRES, Université Catholique de Louvain, 3 place Montesquieu, B-1348 Louvain La Neuve, Belgium, email : vanderlinden@ires.ucl.ac.be,

http://www.ires.ucl.ac.be/CSSSP/home_pa_pers/Vanderlinden/Vanderlinden.html
} 


\section{Introduction}

In recent years, the search-matching model has become a major reference in the economics of unemployment. This approach mainly focuses on the equilibrium implications of frictions and search externalities. Once a worker and a firm have matched, the value of search costs saved by staying together generate a rent that has to be shared. This is done in two ways in the literature. The first one assumes that firms post wage offers that workers take or leave. This paper only considers the second and most commonly-used approach that assumes a bargaining over wages (see Pissarides (2000) for an overview). The search matching approach allows for a synthesis between the micro-determinants of unemployment analyzed by job-search theory, and the macro-determinants of unemployment that highlights real wage rigidities.

The search-matching framework is actually an alternative paradigm to the walrasian one. Since wages are match specific, the notions of a walrasian auctioneer and of competitive equilibria become much less natural. Hence, the two theorems of welfare economics cannot be applied anymore. The optimality of search-matching equilibria is therefore a non-trivial normative issue ${ }^{1}$. When agents are risk neutral, the so-called 'Hosios condition' (Hosios (1990)) is sufficient to guarantee that a laissez faire equilibrium is socially optimal. This condition requires that workers' bargaining power be equal to the elasticity of the matching function with respect to unemployment. Employed workers should receive a certain share of the rent generated by a match in order to compensate them for the cost inherent to job search activities and to prevent the creation of too many vacancies in equilibrium. When the bargaining power does not fulfill the Hosios condition, Boone and Bovenberg (2001a) show how non lump-sum income taxation can be used to decentralize the optimum. Taxation can restore efficiency because a positive marginal tax rate (resp. a negative one) decreases (resp. increases) the share of the surplus that accrues to the workers.

These results hold under the assumption of linear preferences. The social optimum consists then in maximizing total output net of search costs without any concern for the way this output is shared between agents. This is problematic if one thinks that labor market policies should not only reduce the waste of resources due to unemployment but also poverty and inequality generated by unemployment.

This paper revisits the Hosios problem by introducing risk averse workers. Our social welfare criterion deals with insurance against the unemployment risk and with redistribu-

\footnotetext{
${ }^{1}$ In the wage-posting approach, search frictions are necessarily internalized if workers apply to only one offer at the time and are perfectly informed about each firm's wage offer and probability of making an offer. This is the so-called 'competitive search' approach (Moen, 1997).
} 
tion between workers and firm owners. In our model, taxes on labor are levied to finance unemployment benefits and a lump-sum transfer to the firm owner. For tractability matters, we keep the assumption of homogenous labor. Hence, we ignore redistribution among workers with different skills, a topic that is central in the literature following Mirrlees (1971) (e.g. Saez (2001) or Boone and Bovenberg (2001b)). We consider two polar cases characterized by different assumptions about the observability of unemployed workers' job-search intensity.

At the first-best optimum, workers are perfectly insured against the unemployment risk since their search effort can optimally be monitored. To decentralize this optimum, employees should not extract a rent from their match. If their bargaining power is exogenous and positive, a marginal tax rate of $100 \%$ must therefore be implemented. Appropriate levels of unemployment benefits and taxes then prevent the creation of too many vacancies in equilibrium.

The second-best case assumes that unemployed workers freely choose their search intensity. The solution is characterized by an optimal trade off between the provision of incentives to unemployed job seekers and the provision of insurance against the unemployment risk. This is done by selecting an optimal share of the rent for the employees. This moral hazard trade-off has also to take into account firms behavior. We show that, compared to the first-best optimum, the second-best one is characterized by : $i$ ) lower search intensity and a tighter labor market to compensate for the decrease in job search intensity; ii) lower (resp., higher) income for unemployed (resp., employed) workers; iii) a positive rent for the employees. Hence, as in Hosios (1990), the rent sharing rule should be appropriate. An inappropriate bargaining power should be corrected by the introduction of a well-chosen non-zero marginal tax rate in combination with appropriate levels of taxes and of unemployment benefits.

This paper also contributes to the literature on the desirability of progressive labor taxes in equilibrium unemployment models. Malcomson and Sator (1987), Lockwood and Manning (1993), Holmlund and Kolm (1995) and Pissarides (1998 and 2000) among others emphasize that, for a given level of taxes, the negotiated wage is a decreasing function of the marginal tax rate. The higher the marginal tax rate, the lower the increase in after tax wage for a given increase in the negotiated wage, so the lower the pressure for a higher wage. Hence, according to these papers, unemployment can be reduced thanks to a more progressive labor tax schedule. However, the desirability of progressive labor income taxes has been recently questioned by papers that introduce in-work effort (Hansen 1999, Fuest and Huber 2000) or training decisions (Boone and de Mooij 2000). A more progressive tax schedule can reduce productivity per capita so that the total effect on output becomes 
ambiguous. In our model, another mechanism is at work. A more progressive tax schedule reduces the rent extracted by employees. It hence decreases the incentives unemployed people have to search. At the same time however, more progressive taxes allow to better insure against the unemployment risk. In the first-best setting, the former effect does not matter so the optimal marginal tax rate is equal to $100 \%$. In the second-best setting, the optimal trade-off between the two effects leads to an optimal sharing rule. When the bargaining power happens to be too high (respectively, too low), a positive (resp. negative) marginal income tax is needed to decentralize the social optimum. This sheds new light on the pros and cons of progressive income taxation.

We also make a minor contribution to the literature on optimal unemployment insurance (see Holmlund 1998). The seminal articles of Baily (1977) and Mortensen (1977) formulate the search for optimal unemployment insurance as a moral hazard problem where the agent is an unemployed worker whose search intensity is not observable. We extend this partial equilibrium view by including firms behavior and the negotiation of wages. We highlight that non linear taxation and unemployment insurance are complementary instruments to achieve an optimal compromise between risk-sharing and allocative efficiencies on the labor market. The literature about optimal unemployment insurance has already been extended in many directions that we do not consider. On the one hand, Shavell and Weiss (1979) or Hopenhayn and Nicolini (1997) show that unemployment benefits should decrease over the unemployment spell. This result was confirmed by Fredriksson and Holmlund (2001) and was toned down by Cahuc and Lehmann (2000) in general equilibrium search-matching models that endogeneize firms behavior and wage formation. On the other hand, sanctions (i.e. withdrawal of unemployment benefits if search effort is judged insufficient) are an alternative that allows to improve risk-sharing for those who comply with the rules (Boadway and Cuff (1999), Boone and van Ours (2000), Boone et al (2001)). This property is expected to hold as long as search effort is observable at a reasonable cost without (too frequent) errors.

The paper is organized as follows. Section II describes the structure of the economy. Section III is devoted to the equilibrium, Section IV to the first-best optimum and its decentralization, Section V to the second best optimum and its implementation. Section VI concludes.

\section{Assumptions and Notations}

The economy is made of a continuum of homogenous risk-averse workers, a representative risk-neutral firm and the State. There are no financial markets. Workers can either be employed or unemployed. Jobs can either be filled or vacant. Agents are infinitely lived. 
The model is based on the assumption that the matching between unemployed workers and vacant jobs is a time-consuming and costly process due to various frictions on the labor market. Assume a continuous-time setting. The flow of hires $M$ is a function $M(S, v)$ of the number of job-seekers measured in efficiency units $S$ and of the number of vacancies $v$. It is standard to assume that this function is increasing and concave in both arguments (with $M(0, v)=M(S, 0)=0)$ and that returns to scale are constant (see e.g. Pissarides (2000)). Denoting by $e$ the average search intensity and by $u$ the mass of unemployed workers, one has $S=e \cdot u$. Let $\theta \equiv v / S$ be tightness on the labor market (measured in efficiency units). The rate at which a vacant job is filled is $m(\theta)$ with $m(\theta)=\frac{M(S, v)}{v}=M(1 / \theta, 1)$, and $m^{\prime}()<$.0 . An unemployed with search intensity $e_{i} \geq 0$ flows out of unemployment at a rate $e_{i} \cdot \alpha(\theta)=\frac{e_{i}}{e} \cdot \frac{M(e \cdot u, v)}{u}$, with $\alpha(\theta) \equiv M(1, \theta)=\theta \cdot m(\theta)$ and $\alpha^{\prime}(\theta)>0, \alpha^{\prime \prime}()<$.0 . Job matches end at the exogenous rate $q$.

We normalize the size of the labor force to 1 . In steady state, equality between entries and exits yields the "Beveridge curve" equation:

$$
e \cdot \alpha(\theta) \cdot u=q(1-u) \quad \Leftrightarrow \quad u=\frac{q}{q+e \cdot \alpha(\theta)}
$$

that negatively links the unemployment rate to tightness $\theta$.

Let $r$ be the discount rate common to workers and firms. An employed worker has an instantaneous utility function $v(\omega)$, where $\omega$ denotes her after-tax income. An unemployed worker has an instantaneous utility $v(z-d(e))$ where $z$ denotes her untaxed unemployment benefits. We assume $v^{\prime}()>0,. d() \geq 0,. d^{\prime}()>$.0 and $d^{\prime \prime}(.) \geq 0\left(\right.$ with $\lim _{e \rightarrow 0} d^{\prime}(e)=0$ and $\left.\lim _{e \rightarrow \infty} d^{\prime}(e)=+\infty\right)$. The risk aversion assumption implies $v^{\prime \prime}()<$.0 . For the unemployed, a possible interpretation of our specification is that $d(e)$ denotes the monetary cost of job-search activities. Then, $z-d(e)$ would stand for the net level of consumption of the unemployed. However, on top of expenses related to job-search activities, $d(e)$ can also capture the disutility of search effort.

The representative firm is made of $L$ filled jobs and $v$ vacant jobs. Each filled job produces a flow of $y$ units of output, whereas each vacant job costs $c$ per unit of time. With a normalized labor force, one ex-post has $L=1-u$. $\chi$ is a lump-sum transfer or tax paid to or by the representative firm, with $\chi \lessgtr 0$. This lump-sum transfer allows for a redistribution between workers and the firm owner. The representative firm-owner's income flow is:

$$
\Pi=(1-u)(y-w)-c \cdot v+\chi
$$

where $w$ is the gross wage.

A $\operatorname{tax} T$ is levied on each filled job by the government, with $T=w-\omega$. These resources are used to finance unemployed benefits $z$ and the transfer to the firm-owner $\chi$. At any 
point in time, the public budget is balanced according to:

$$
T(1-u)=u \cdot z+\chi \quad \Leftrightarrow \chi=T(1-u)-u \cdot z
$$

This budget constraint together with (2) gives the following aggregate resource constraint:

$$
(1-u) \omega+z \cdot u+\Pi+c \cdot v=(1-u) y
$$

Rearranging this expression one gets

$$
(1-u) \omega+u(z-d(e))+\Pi=Y
$$

where $Y \equiv(1-u) y-u \cdot d(e)-c \cdot v$ stands for total output net of search and vacancy costs. "Efficiency" will be achieved when $Y$ is maximized. The redistribution problem consists in sharing this net output between employed workers $(\omega)$, unemployed workers $(z-d(e))$ and the firm-owner $(\Pi)$.

\section{The Market equilibrium}

\section{III.1 The representative firm}

Intertemporal profits as of time $t$ are:

$$
\mathbb{P}_{t}=\int_{t}^{+\infty} e^{-r(\tau-t)} \cdot \Pi_{\tau} \cdot d \tau
$$

At time $t=0$, the representative firm-owner maximizes:

$$
\max _{v} \mathbb{P}_{0} \quad \text { s.t. } \quad \dot{L}=m(\theta) \cdot v-q \cdot L
$$

taking tightness $\theta$ as given. Since marginal productivity $y$ is constant, the same conditions would be reached in the standard model where each firm holds only one job. In this case, let $J$ denotes the intertemporal expected value of a filled vacancy and $J^{v}$ the expected value of an open vacancy. $J$ and $J^{v}$ verify the following equations:

$$
\begin{aligned}
r \cdot J-\dot{J} & =y-w+q\left(J^{v}-J\right) \\
r \cdot J^{v}-\dot{J}^{v} & =-c+m(\theta)\left(J-J^{v}\right)
\end{aligned}
$$

Assuming free entry of vacancies, a steady-state equilibrium should be characterized by $J^{v}=\dot{J}^{v}=0$. Hence, in such an equilibrium:

$$
J=\frac{c}{m(\theta)}=\frac{y-w}{r+q}
$$

This leads to:

$$
w=\phi(\theta) \equiv y-\frac{c(r+q)}{m(\theta)}
$$


This relationship between the gross wage $w$ and tightness $\theta$ is downward-sloping. The higher is $w$, the lower is the value of a filled job $J$ and the lower is the number of vacancies in the economy and hence the lower is tightness $\theta$. Since $\theta$ is measured in efficiency units, one should note that this relation does not depend on search intensity $e$.

\section{III.2 Search Behavior}

Let $V$ and $V^{u}$ denote the expected lifetime utility of respectively an employed and an unemployed worker. $V$ solves:

$$
r \cdot V-\dot{V}=v(w-T)+q\left(V^{u}-V\right)
$$

Two cases will be considered. The one where search intensity is observable will be introduced later. When search cannot be observed, an unemployed worker has to choose her search intensity at any point in time. With a search intensity $e_{i}$, her instantaneous utility is $v\left(z-d\left(e_{i}\right)\right)$ and her expected "capital gain" is $e_{i} \cdot \alpha(\theta)\left(V-V^{u}\right)$. Hence, the effort level is the solution of:

$$
r \cdot V^{u}-\dot{V}^{u}=\max _{e_{i}}\left\{v\left(z-d\left(e_{i}\right)\right)+e_{i} \cdot \alpha(\theta)\left(V-V^{u}\right)\right\}
$$

where $V, V^{u}, \dot{V}^{u}$ and $\theta$ are taken as given. The first-order condition of this problem is ${ }^{2}$ :

$$
0=\alpha(\theta)\left(V-V^{u}\right)-d^{\prime}(e) \cdot v^{\prime}(z-d(e))
$$

At a steady state where $\dot{V}=\dot{V}^{u}=0$, equation (13) together with equations (11) and (12) implicitly define the optimal search level $e$ according to $0=S(\theta, w, e)$ with:

$$
S(\theta, w, e) \equiv \alpha(\theta)(v(w-T)-v(z-d(e)))-d^{\prime}(e) \cdot v^{\prime}(z-d(e))(r+q+e \cdot \alpha(\theta))
$$

It can be verified (see Appendix 1) that the following partial derivatives have unambiguous signs ${ }^{3}: S_{e}^{\prime}<0, S_{w}^{\prime}>0, S_{\theta}^{\prime}>0$. Therefore, the optimal search intensity increases with $w$ and $\theta$. It can be checked that an increase in $T$ lowers search intensity (since $\left.S_{T}^{\prime}=-S_{w}^{\prime}<0\right)$ while a rise in the level of unemployment benefits has an ambiguous effect on $e$. With the chosen instantaneous utility function, an increase in $z$ reduces the marginal disutility of search effort ${ }^{4}$. It also decreases the marginal gain of search. Hence the ambiguous net effect on $e$.

\footnotetext{
${ }^{2}$ The second-order condition is satisfied since $d^{\prime \prime}() \geq$.0 and $v^{\prime \prime}()<$.0 . It should be noticed that similar conclusions would be obtained if the utility of unemployed worker $i$ was denoted by $v\left(z-c_{i}\right)$ and if her exit rate from unemployment was written as $p\left(c_{i}\right) \cdot \alpha(\theta)$, provided that $c \equiv d(e)$ and $p(.) \equiv d^{-1}($.$) .$

${ }^{3}$ For any function $f(., \ldots,),. f_{x}^{\prime}$ denotes the partial derivatives of $f$ with respect to $x$.

${ }^{4}$ This effect would not be present if the instantaneous utility function was separable.
} 
Microeconometric estimations generally lead to the conclusion that the individual exit rate out of unemployment is negatively affected by the level of unemployment benefits. From this evidence, the case where:

$$
S_{z}^{\prime}<0
$$

is the most plausible one (see Layard et al 1991 and Holmlund 1998 among others).

\section{III.3 The Wage Bargain}

A match generates a surplus that is shared between the worker and the firm-owner. Let $\gamma$ be the exogenous bargaining power of the worker, with $0<\gamma<1$. The gross wage rate maximizes the following Nash product:

$$
\max _{w}\left(V-V^{u}\right)^{\gamma}\left(J-J^{v}\right)^{1-\gamma}
$$

The level of taxes $T$ is a function of the gross wage $w$. The wage setters realize that a marginal rise of the gross wage of an amount $\Delta w$ changes the level of taxes by $T_{m} \cdot \Delta w$, where $T_{m}$ denotes the marginal tax rate. Taking this relationship and $\theta$ as given, the first-order condition of the previous maximization can be written as :

$$
V-V^{u}=\frac{\gamma\left(1-T_{m}\right)}{1-\gamma} \cdot v^{\prime}(w-T) \cdot\left(J-J^{v}\right)
$$

Let $\hat{\gamma}$ be such that:

$$
\frac{\hat{\gamma}}{1-\hat{\gamma}}=\frac{\gamma\left(1-T_{m}\right)}{1-\gamma}
$$

$\hat{\gamma}$ denotes the employees' actual bargaining power taking into account the negative effect of the marginal tax rate on their effective bargaining strength. For given tightness $\theta$, search intensity $e$, bargaining power $\gamma$ and level of taxes $T$, a higher marginal tax rate lowers the change in the after tax wage resulting from a given increase in the negotiated gross wage. This lowers the employees' rent $V-V^{u}$ and eventually leads to wage moderation (see e.g. Malcomson and Sator (1987), Lockwood and Manning (1993)).

Combining (16) with (11) and (12) and the free entry condition (9) yields at a steady state $W S(\theta, w, e)=0$ with :

$$
W S(\theta, w, e) \equiv v(w-T)-v(z-d(e))-\frac{\gamma\left(1-T_{m}\right)}{1-\gamma} \cdot \frac{r+q+e \cdot \alpha(\theta)}{m(\theta)} \cdot c \cdot v^{\prime}(w-T)
$$

This equation defines the wage-setting curve. From Appendix 1 one has: $W S_{\theta}^{\prime}<0$, $W S_{w}^{\prime}>0, W S_{e}^{\prime}=-\frac{S(\theta, w, e)}{r+q+e \cdot \alpha(\theta)}, W S_{T}^{\prime}<0, W S_{T_{m}}^{\prime}>0$ and $W S_{z}^{\prime}<0$. Conditional on $e$, the wage-setting curve is therefore upward-sloping in a $(\theta, w)$ space. If the marginal tax 
rate is fixed and $\theta$ and $e$ are given, increasing the level of taxes $T$ raises the net wage rate. On the contrary, for given levels of taxes $T$, tightness $\theta$ and search intensity $e$, a more progressive tax schedule will put a downward pressure on the negotiated wage. More generous unemployment benefits have the usual positive effect on wages.

\section{III.4 Steady state Equilibrium}

Conditional on $z, T, T_{m}, \gamma$, or equivalently, conditional on $z, T, \hat{\gamma}$, a steady-state equilibrium $(\theta, w, e)$ is a solution of the system:

$$
w=\phi(\theta) \quad S(\theta, w, e)=0 \quad W S(\theta, w, e)=0
$$

where $\phi(),. S(., .,$.$) and W S(., .,$.$) are respectively defined in (10), (14) and (18). Equa-$ tion (1) then gives the unemployment rate $u$ and consequently the rate of vacant jobs $v$. Finally, equation (3) sets the level of the transfer to the representative firm-owner $\chi$.

The equilibrium can be characterized in a more simple way by defining functions $\mathbb{S}(\theta, e) \equiv S(\theta, \phi(\theta), e)$ and $\mathbb{W}(\theta, e) \equiv W S(\theta, \phi(\theta), e)$. Since equation (10) depends neither on search intensity $e$ nor on policy parameters $\left(z, T, T_{m}\right)$, one gets $\mathbb{S}_{e}^{\prime}(\theta, e)=$ $S_{e}^{\prime}(\theta, \phi(\theta), e)<0, \mathbb{S}_{x}^{\prime}(\theta, e)=S_{x}^{\prime}(\theta, \phi(\theta), e)$ for $x=z, T, T_{m}$. Similarly, one has $\mathbb{W}_{\theta}^{\prime}(\theta, e)<0, \mathbb{W}_{e}^{\prime}(\theta, e)=W_{e}^{\prime}(\theta, \phi(\theta), e)=-\frac{\mathbb{S}(\theta, e)}{r+q+e \cdot \alpha(\theta)}$ and $\mathbb{W}_{x}^{\prime}(\theta, e)=W_{x}^{\prime}(\theta, \phi(\theta), e)$ for $x=z, T, T_{m}$. Appendix 2 shows that the system $\mathbb{S}(\theta, e)=\mathbb{W}(\theta, e)=0$ admits at most one solution, so the equilibrium (if any ${ }^{5}$ ) is unique. Hence, the issue of multiple equilibria is ruled out. A vector $\left(z, T, T_{m}, \gamma\right)$ that decentralizes an optimum $(\theta, w, e)$ then necessarily leads to this optimal solution. This property will be very convenient later on when optima will be decentralized.

Exploiting the property that in equilibrium $\mathbb{W}_{e}^{\prime}=0$, Appendix 2 shows that:

$$
d \theta=-\frac{\mathbb{W}_{z}^{\prime}}{\mathbb{W}_{\theta}^{\prime}} d z-\frac{\mathbb{W}_{T}^{\prime}}{\mathbb{W}_{\theta}^{\prime}} d T-\frac{\mathbb{W}_{T_{m}}^{\prime}}{\mathbb{W}_{\theta}^{\prime}} d T_{m}
$$

Since $\mathbb{W}_{\theta}^{\prime}<0, \mathbb{W}_{z}^{\prime}<0, \mathbb{W}_{T}^{\prime}<0, \mathbb{W}_{T_{m}}^{\prime}>0$ one has $d \theta / d z<0, d \theta / d T<0$ and $d \theta / d T_{m}>0$. These results generalize earlier results of Pissarides $(1998,2000)$ and Fredriksson and Holmlund (2001). The direction in which the equilibrium values of tightness and wage vary with the policy parameters is entirely determined by the sign of their partial effects on the wage setting curve $\mathbb{W}(.,$.$) , independently of search behavior. Finally,$ Appendix 2 explains why the marginal effect of $T$ and $T_{m}$ on $e$ can only be signed if $\hat{\gamma}$ is equal to the elasticity of the matching function with respect to unemployment. General and partial equilibrium effects on $e$ then coincide. Otherwise, in general, we cannot conclude about the net effects of these policy parameters on search intensity.

\footnotetext{
${ }^{5}$ Existence is not always guaranteed. This occurs for instance if $z>y$. Notice that an equilibrium exists for some values of the parameters since Lehmann and Van der Linden (2002) are able to simulate it.
} 
Proposition 1 There is (at most) a single steady-state equilibrium in this economy. At the equilibrium, tightness $\theta$ (respectively, the gross wage $w$ ) decreases (resp. increases) with the levels of unemployment benefits $z$ and tax $T$ and increases (resp. decreases) with the marginal tax rate $T_{m}$.

\section{The First-Best optimum}

In this section, we first look at the optimal allocation of resources that a benevolent social planner would implement if he could perfectly control search intensity. This section then explains how to decentralize this optimum.

\section{IV.1 The central planner problem}

Consider a benevolent planner in charge of the unemployment insurance and the redistribution systems. For the reasons given in the introduction, we assume that the planner is concerned with the following social criterion $\Omega$ :

$$
\Omega=(1-u) V+u \cdot V^{u}+\eta \cdot \mathbb{P}
$$

This criterion $\Omega$ is a utilitarian objective that adds two components. The first one, $(1-u) V+u \cdot V^{u}$, is the sum of the inter-temporal utilities of employed and unemployed workers weighted by their numbers. The second component is the inter-temporal profit of the representative firm-owner weighted by a parameter $\eta>0$. This parameter is therefore the (constant) social marginal value of profits. The first component of $\Omega$ can also be reinterpreted in an ex-ante perspective as the expected utility of a representative worker who is aware that she will be unemployed with a probability ${ }^{6} u$ and employed with probability $1-u$. In what follows, we privilege the insurance interpretation and the expression "redistribution" will designate the way net income is shared between the firm-owner and the workers taken as a whole. We assume that the planner maximizes the present certainty equivalent of $\Omega$, namely $r \cdot \Omega$.

Appendix 3 then shows that:

$$
\Omega=\int_{t=0}^{+\infty} e^{-r t}\{(1-u) v(\omega)+u \cdot v(z-d(e))+\eta \cdot \Pi\} d t
$$

At the steady state, maximizing $r \cdot \Omega$ is equivalent to maximizing $(1-u) v(\omega)+u$. $v(z-d(e))+\eta \cdot \Pi$. For simplicity, it is standard to ignore the transitional dynamics and to consider that $r \rightarrow 0$. The social planner therefore maximizes $(1-u) v(\omega)+u$.

\footnotetext{
${ }^{6}$ The reinterpretation of $u$ as a probability is made possible by our normalization to 1 of the (exogenous) size of the labor force.
} 
$v(z-d(e))+\eta \cdot \Pi$. It is reasonable to impose a nonnegative ${ }^{7}$ value for $\Pi$. However, a constraint $\Pi \geq 0$ will not explicitly be imposed in the following maximization problems. It is implicitly assumed that the exogenous value of $\eta$ is sufficiently high so that $\Pi$ is nonnegative at the optimum. Taking the resource constraint (4) and the flow equilibrium equation (1) into account and remembering that $v=e \cdot \theta \cdot u$, the planner's program then consists in ${ }^{8}$ :

$$
\begin{aligned}
& \max _{\theta, \omega, u, z, e}(1-u) \cdot v(\omega)+u \cdot v(z-d(e))+\eta \cdot[(1-u)(y-\omega)-(z+c \cdot e \cdot \theta) u](21) \\
& \text { s.t. : } e \cdot \alpha(\theta) \cdot u=q(1-u)
\end{aligned}
$$

Introducing subscript 1 to denote the first-best optimum and denoting $\delta_{1}$ the Lagrange multiplier, the first order conditions with respect to $\omega, z, e, u, \theta$ are respectively:

$$
\begin{aligned}
& 0=\left(1-u_{1}\right)\left[v^{\prime}\left(\omega_{1}\right)-\eta\right] \\
& 0=u_{1}\left[v^{\prime}\left(z_{1}-d\left(e_{1}\right)\right)-\eta\right] \\
& 0=u_{1}\left[-v^{\prime}\left(z_{1}-d\left(e_{1}\right)\right) \cdot d^{\prime}\left(e_{1}\right)-\eta \cdot c \cdot \theta_{1}+\delta_{1} \cdot \alpha\left(\theta_{1}\right)\right] \\
& 0=v\left(z-d\left(e_{1}\right)\right)-v\left(\omega_{1}\right)+\eta\left(\omega_{1}-y-z_{1}-c \cdot e_{1} \cdot \theta_{1}\right)+\delta_{1}\left(e_{1} \cdot \alpha\left(\theta_{1}\right)+q\right) \\
& 0=-c \cdot e_{1} \cdot \eta \cdot u_{1}+\delta_{1} \cdot e_{1} \cdot \alpha^{\prime}\left(\theta_{1}\right) \cdot u_{1}
\end{aligned}
$$

Equations (22) and (23) imply that:

$$
v^{\prime}\left(\omega_{1}\right)=v^{\prime}\left(z_{1}-d\left(e_{1}\right)\right)=\eta
$$

Hence:

$$
\omega_{1}=z_{1}-d\left(e_{1}\right)
$$

Under perfect information, the social planner can perfectly insure workers against the unemployment risk. With the instantaneous utility functions chosen above, this is achieved by making workers indifferent between the unemployment and employment states ${ }^{9}$. Conditions (24) (25) and (26) can therefore be respectively rewritten as:

$$
\left(\frac{\delta_{1}}{\eta}=\right) \frac{d^{\prime}\left(e_{1}\right)+c \cdot \theta_{1}}{\alpha\left(\theta_{1}\right)}=\frac{y+d\left(e_{1}\right)+e_{1} \cdot c \cdot \theta_{1}}{e_{1} \cdot \alpha\left(\theta_{1}\right)+q}=\frac{c}{\alpha^{\prime}\left(\theta_{1}\right)}
$$

Consequently, the optimal levels of tightness and search intensity are defined by a system of two equations that are independent of $\eta$. Put another way, the optimal level of

\footnotetext{
${ }^{7}$ When $r$ tends to 0 , it can be checked that $\Pi$ tends to $\chi$ at equilibrium.

${ }^{8}$ Formally, one should maximize $\Omega$ with $r>0$ under the dynamical constraint $\dot{u}=q(1-u)-e \cdot \alpha(\theta) \cdot u$, derive the first-order and enveloppe conditions and take the limits of those conditions for $r \rightarrow 0$. It can be verified that this method and the maximization of the following problem give the same results for $r \rightarrow 0$.

${ }^{9}$ If unemployment workers' instantaneous utility was $v(z)-d(e)$, the first best would equalize instantaneous incomes instead of utilities.
} 
$\theta$ and $e$ can be chosen irrespectively of the way net output is shared between the workers and the representative firm-owner.

From equalities in (28), we get that the social optimum is determined by either $F\left(\theta_{1}, e_{1}\right)=G\left(\theta_{1}, e_{1}\right)=0$, or $F\left(\theta_{1}, e_{1}\right)=H\left(\theta_{1}, e_{1}\right)=0$ or $G\left(\theta_{1}, e_{1}\right)=H\left(\theta_{1}, e_{1}\right)=0$, where:

$$
\begin{aligned}
F(\theta, e) & \equiv \alpha^{\prime}(\theta)\left(d^{\prime}(e)+c \cdot \theta\right)-c \cdot \alpha(\theta) \\
G(\theta, e) & \equiv \alpha(\theta)(y+d(e)+c \cdot \theta \cdot e)-\left(c \cdot \theta+d^{\prime}(e)\right)(e \cdot \alpha(\theta)+q) \\
H(\theta, e) & \equiv \alpha^{\prime}(\theta)(y+d(e)+e \cdot c \cdot \theta)-c(e \cdot \alpha(\theta)+q)
\end{aligned}
$$

Conditional upon the optimal conditions $(27)$, function $H(\theta, e)$ implicitly defines the optimal level of tightness as a function of search intensity whereas function $G(\theta, e)$ implicitly defines the optimal level of search intensity as a function of tightness.

Appendix 4 first shows that $F_{\theta}^{\prime}<0$ and $F_{e}^{\prime}>0$. Consequently, function $F(.,$.$) is$ upward-sloping in the $(\theta, e)$ plane (see figure 1). Second, we show that $G_{e}^{\prime}<0$ and $G_{\theta}^{\prime}=\frac{q}{\alpha(\theta)} F(\theta, e)$. Consequently, in the $(\theta, e)$ plane function $G(.,$.$) is upward-sloping$ (respectively downward-sloping) at the left (respectively at the right) of function $F(.,$. and intersects function $F(.,$.$) horizontally (see figure 1). Third, we show that H_{\theta}^{\prime}<0$ and $H_{e}^{\prime}=F(\theta, e)$. Hence, in the $(\theta, e)$ space, function $H(.,$.$) is upward-sloping (re-$ spectively downward-sloping) above (respectively below) function $F(.,$.$) and intersects$ function $F(.,$.$) vertically (see Figure 1). This configuration guarantees the unicity of a$ solution to the system $(28)^{10}$.

We now show that the first-best solution $\left(e_{1}, \theta_{1}, u_{1}\right)$ maximizes total output net of search costs $Y$ :

$$
\begin{aligned}
\max _{e, u, \theta} \quad Y & =(1-u) y-u \cdot d(e)-c \cdot e \cdot \theta \cdot u \\
\text { s.t. } & : \quad e \cdot \alpha(\theta) \cdot u=q(1-u)
\end{aligned}
$$

Denoting $\delta^{Y}$ the Lagrange multiplier, the first-order conditions are:

$$
\left(\delta^{Y}=\right) \frac{d^{\prime}(e)+c \cdot \theta}{\alpha(\theta)}=\frac{y+d(e)+e \cdot c \cdot \theta}{e \cdot \alpha(\theta)+q}=\frac{c}{\alpha^{\prime}(\theta)}
$$

Comparing these expressions with $(28)$, it is obvious that the solution $(e, \theta)$ to problem (29) is exactly the first-best optimum $\left(e_{1}, \theta_{1}\right)$. Hence, the unemployment rate $u$ is equal to $u_{1}$. At the first-best optimum, total output net of costs is therefore maximized. Consequently, efficiency and equity goals can be achieved separately. The following proposition summarizes the principal results of this section:

\footnotetext{
${ }^{10}$ The proof of the unicity of the solution to $F(\theta, e)=H(\theta, e)=0$ is similar to the proof of the unicity of equilibrium. One simply has to replace $\mathbb{S}$ by $-F$ and $\mathbb{W}$ by $H$.
} 


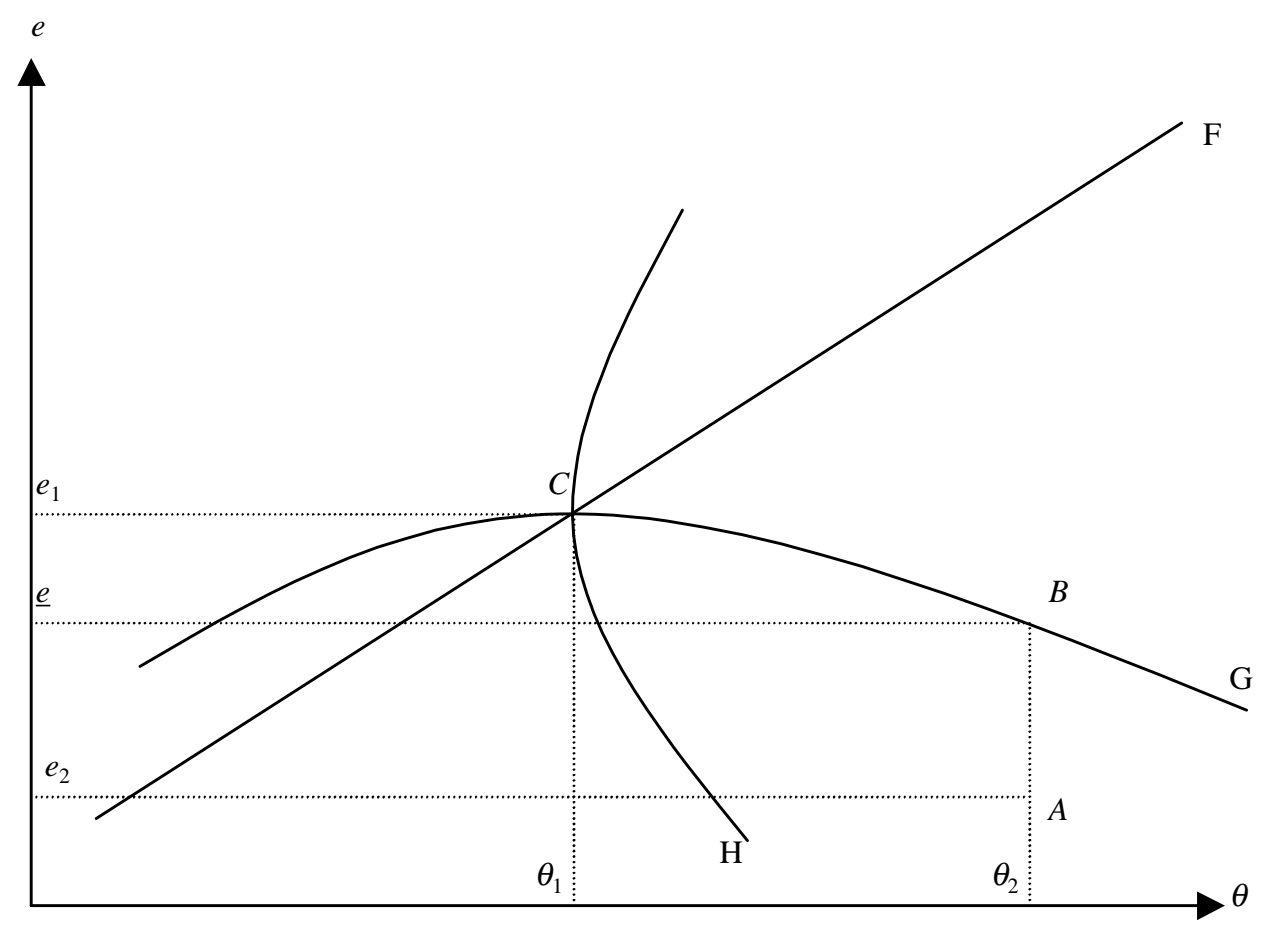

Figure 1: The first-best choice of $(\theta, e)$

Proposition 2 Under perfect information, the central planner is able to deal separately with allocative efficiency and with the risk-sharing and redistributive objectives. The firstbest levels of search effort and tightness maximize total output net of costs. Given these optimal levels, the first-best income levels guarantee a constant level of utility whether workers are employed or not. This level is higher the lower the social weight attributed to profits.

\section{IV.2 Decentralization of the First-Best optimum}

In this section, we describe the policies required to decentralize the first-best optimum. Given the unemployment benefits $z$, tax level $T$, marginal tax rate $T_{m}$ and search intensity $e$, the equilibrium solves $w=\phi(\theta)$ and $W S(\theta, w, e)=0$. The steady-state level of unemployment $u$ is then given by equation (1).

To implement the first-best optimum, the State has to decentralize an equilibrium in which workers are perfectly insured against the unemployment risk. According to (18), implementing this equilibrium requires $\hat{\gamma}_{1}=0$. Such a low actual bargaining power is unavoidable to prevent insiders from extracting a rent $V-V^{u}>0$ though wage bargaining. Whenever the bargaining power $\gamma$ is positive, this can only be achieved with a marginal 
tax rate $T_{m, 1}=1$ (see equation (17)). So, the decentralization of the first-best optimum is then impossible without an 'extremely' progressive income tax schedule.

The State can fix the level of unemployment benefits to $z_{1}$. By assumption, it is also able to impose a search intensity $e_{1}$. Therefore, employed workers earn a net income equal to the first-best one: $\omega_{1}=z_{1}-d\left(e_{1}\right)$. Knowing the optimal value $\theta_{1}$, let then the level of tax be given by $T_{1}=\phi\left(\theta_{1}\right)-\omega_{1}$. Since, $\hat{\gamma}_{1}=0, z=z_{1}$ and $e=e_{1}$, the wage bargaining process implies $w=w_{1}=\omega_{1}+T_{1}$ according to (18). Given this gross wage, the representative firm chooses its optimal level of vacancies until the free-entry condition (9) is met. The equivalence between the free-entry condition (9) and equation (10) guarantees that $\theta$ solves equation $w_{1}=\phi(\theta)$, which has a unique solution, namely $\theta_{1}$.

Proposition 3 Under perfect information, the State can always decentralize the firstbest optimum with a zero actual bargaining power for the workers $\left(\hat{\gamma}_{1}=0\right)$. When their bargaining power $\gamma$ is positive, the marginal tax rate should be equal to $100 \%$.

One may wonder why the decentralization with risk averse workers differ so much from the one under linear preferences (i.e. with $v^{\prime \prime}()=$.0 and $\left.v^{\prime}(.) \equiv \eta\right)$. In the latter case, the social planner is only concerned with total output net of search costs $Y$ (defined in equation (5)), independently of the way this output is shared between the employed, the unemployed and the firm owner. There is therefore a multiplicity of first-best optima. Any combination of $\omega, z$ and $\Pi$ leading to the same total output $Y_{1}$ is actually a first-best optimum in this case. Among this infinite number of optima, one usually selects a specific one, namely the one that can be decentralized without State intervention. Decentralizing this laissez-faire economy with a bargaining power satisfying the Hosios condition yields only one of these optima, namely the one where $z=T=0$ and $\omega_{1}=w_{1}>0$. When preferences tend to the linear case, our decentralization approach leads to another optimum with $z=z_{1}=\omega_{1}+d\left(e_{1}\right)>0$.

\section{The second-Best optimum}

\section{V.1 The central planner problem}

In this section, we consider the more realistic case where search intensity is not observed by the State. As in the first best, the tax system and the level of unemployment benefits are the instruments used to promote efficiency and equity. But now the State faces a moral hazard problem. An incentive constraint concerning unemployed workers' search behavior should now be taken into account by the State. Since $r$ tends to 0 , this behavior 
is described at the steady state by:

$$
d^{\prime}(e) \cdot v^{\prime}(z-d(e))(q+e \cdot \alpha(\theta))=\alpha(\theta)(v(\omega)-v(z-d(e)))
$$

According to equations (11), (12) (13), $\omega=w-T$. The second-best optimization consists in problem (21) extended to include this incentive constraint (30), namely:

$$
\begin{aligned}
& \max _{\theta, \omega, u, z, e}(1-u) \cdot v(\omega)+u \cdot v(z-d(e))+\eta[(1-u)(y-\omega)-z \cdot u-c \cdot e \cdot \theta \cdot u] \\
& 0=e \cdot \alpha(\theta) \cdot u-q(1-u) \\
& 0=\alpha(\theta)(v(\omega)-v(z-d(e)))-d^{\prime}(e) \cdot v^{\prime}(z-d(e))(q+e \cdot \alpha(\theta))
\end{aligned}
$$

Introducing subscript 2 to denote the second-best optimum, let $\delta_{2}$ (respectively $\psi_{2}$ ) denote the Lagrange multiplier associated with the flow equilibrium (respectively the incentive constraint). The first order conditions with respect to $\omega, z, e, u$ and $\theta$ are respectively:

$$
\begin{aligned}
0= & \left(1-u_{2}\right)\left[v^{\prime}\left(\omega_{2}\right)-\eta\right]+\psi_{2} \cdot \alpha\left(\theta_{2}\right) \cdot v^{\prime}\left(\omega_{2}\right) \\
0= & u_{2}\left[v^{\prime}\left(z_{2}-d\left(e_{2}\right)\right)-\eta\right] \\
& -\psi_{2}\left\{\alpha\left(\theta_{2}\right) \cdot v^{\prime}\left(z_{2}-d\left(e_{2}\right)\right)+v^{\prime \prime}\left(z_{2}-d\left(e_{2}\right)\right) \cdot d^{\prime}\left(e_{2}\right) \cdot\left(q+e_{2} \cdot \alpha\left(\theta_{2}\right)\right)\right\} \\
0= & u_{2}\left[-d^{\prime}\left(e_{2}\right) \cdot v^{\prime}\left(z_{2}-d\left(e_{2}\right)\right)-\eta \cdot c \cdot \theta_{2}+\delta_{2} \cdot \alpha\left(\theta_{2}\right)\right] \\
& +\psi_{2}\left\{-d^{\prime \prime}\left(e_{2}\right) \cdot v^{\prime}\left(z_{2}-d\left(e_{2}\right)\right)+\left(d^{\prime}\left(e_{2}\right)\right)^{2} \cdot v^{\prime \prime}\left(z_{2}-d\left(e_{2}\right)\right)\right\}\left(q+e_{2} \cdot \alpha\left(\theta_{2}\right)\right) \\
0= & v\left(z_{2}-d\left(e_{2}\right)\right)-v\left(\omega_{2}\right)+\eta\left(\omega_{2}-y-z_{2}-c \cdot e_{2} \cdot \theta_{2}\right)+\delta_{2}\left(e_{2} \cdot \alpha\left(\theta_{2}\right)+q\right) \\
0= & -c \cdot e_{2} \cdot \eta \cdot u_{2}+\delta_{2} \cdot \alpha^{\prime}\left(\theta_{2}\right) \cdot e_{2} \cdot u_{2}+ \\
& \psi_{2} \cdot \alpha^{\prime}\left(\theta_{2}\right) \cdot\left\{v\left(\omega_{2}\right)-v\left(z_{2}-d\left(e_{2}\right)\right)-e_{2} \cdot d^{\prime}\left(e_{2}\right) \cdot v^{\prime}\left(z_{2}-d\left(e_{2}\right)\right)\right\}
\end{aligned}
$$

If preferences were linear (i.e. with $v^{\prime} \equiv \eta$ ), equations (31) and (32)would imply that $\psi_{2}=0$. Hence, the three last conditions (33) to (35) would exactly correspond to those found in the first-best case. So, one gets $e_{2}=e_{1}, \theta_{2}=\theta_{1}, u_{2}=u_{1}$ and thereby $Y_{2}=Y_{1}$. The second best would maximize total output net of costs and the incentive constraint (30) would then specify the difference in income between employed and unemployed workers.

Under risk aversion, the incentive constraint (30) implies that $\omega_{2}>z_{2}-d\left(e_{2}\right)$. Therefore, $v^{\prime}\left(\omega_{2}\right)<v^{\prime}\left(z_{2}-d\left(e_{2}\right)\right)$. Hence, according to (31) and (32), the property $\psi_{2} \neq 0$ is required. Appendix 5 explains why $\psi_{2}>0$. Moreover, Appendix 5 shows that $G\left(\theta_{2}, e_{2}\right)>0$ and $H\left(\theta_{2}, e_{2}\right)<0$. Remembering the properties of functions $G$ and $H$, these properties immediately imply the following inequalities:

$$
e_{2}<e_{1} \quad \text { and } \quad \theta_{2}>\theta_{1}
$$


The intuition behind these properties is the following. Because of moral hazard, there is now a trade-off between efficiency and equity goals. To induce search effort, employed workers necessarily enjoy higher utility levels than unemployed ones at the second best. Keeping search effort at its first-best level would however require a difference in utilities between employed and unemployed workers that would be too detrimental to the objective of insurance, hence $e_{2}<e_{1}$. Compared to the first-best optimum, the social planner integrates the beneficial effect of a tighter labor market on search effort. An increase in tightness allows to relax the incentive constraint. This intuitively explains why $\theta_{2}>\theta_{1}$. This implies that the expected cost of filling a vacancy $c / m(\theta)$ is too high at the secondbest optimum. Since tightness is measured in efficiency units, these properties have no clear implications on the comparison between $v_{2} / u_{2}$ and $v_{1} / u_{1}$.

Comparing conditions (31) with (22) yields $\omega_{2}>\omega_{1}$. In the most plausible case where higher unemployment benefits have a negative impact on search effort, i.e. when $S_{z}^{\prime}<0$, condition (32) and (23) leads to $z_{2}-d\left(e_{2}\right)<z_{1}-d\left(e_{1}\right)$. Since, $e_{2}<e_{1}$, these results imply $z_{2}<z_{1}$. The intuition behind $z_{2}-d\left(e_{2}\right)<z_{1}-d\left(e_{1}\right)$ and $\omega_{2}>\omega_{1}$ is similar to the one underlying $\theta_{2}>\theta_{1}$. Compared to the first best, the social planner integrates the beneficial effect of a higher (respectively, a lower) utility level for employed (respectively, unemployed) workers on search effort.

One can compare the total output net of cost $Y$ at the first-best and at the second-best optima. We have shown that the first-best levels of tightness and search intensity $\theta_{1}, e_{1}$ maximize $Y$. Search intensity and tightness differ at the second-best compared to their first-best optima. Hence one has $Y_{2}<Y_{1}$.

The following proposition summarizes our main results.

Proposition 4 When search effort in unobservable, allocative efficiency, risk-sharing efficiency and redistributive objectives cannot be achieved separately anymore. Compared to the first-best optimum, the second-best one is characterized by lower search effort $e$ and total net output $Y$ and by higher tightness $\theta$ and net income in employment $\omega$.

To end this section, let us briefly emphasize how this general equilibrium analysis enriches partial equilibrium studies such as Baily (1977). In a partial equilibrium framework, both $\theta$ and $w$ are exogenous. So, any conclusion is necessarily contingent on the values taken by $\theta$ and $w$. Let us assume that they are fixed at their second best optimal value ${ }^{11}$. Recall that $G(\theta, e)=0$ defines the level of search intensity that maximizes net output $Y$ conditional on $\theta$. In a partial equilibrium perspective, the loss in efficiency when search effort is unobservable can be captured by the distance between the second-best optimum

\footnotetext{
${ }^{11}$ The second-best value of the wage rate will be made precise in the following sub-section.
} 
$e_{2}$ and the solution $\underline{e}$ to equation $G\left(\theta_{2}, e\right)=0$. This can be illustrated in Figure 1 where this distance is A-B. In a general equilibrium framework, the loss due to the unobservability of search effort is larger because now the second-best outcome, A in Figure 1, has to be compared to the first-best $\mathrm{C}$ where search effort $e_{1}$ is higher than $\underline{e}$ and less vacancies have to be posted per unemployed worker (measured in efficiency units): $\theta_{1}<\theta_{2}$.

\section{V.2 Decentralization of the second best}

To decentralize the second-best optimum, the policy parameters should necessarily solve $z=z_{2}, T_{2}=\phi\left(\theta_{2}\right)-\omega_{2}$ and $W S\left(\theta_{2}, \phi\left(\theta_{2}\right), e_{2}\right)=0$. This obviously gives a single vector of policy parameters $\left(z_{2}, T_{2}, T_{m, 2}\right)$. According to Proposition 1 , we know that a single equilibrium exists for any vector of policy parameters. Hence for the policy parameters $\left(z_{2}, T_{2}, T_{m, 2}\right)$, we know that the second-best optimum is decentralized.

To implement the second-best optimum ${ }^{12}$, the State has to decentralize an equilibrium in which employed workers are better off than unemployed people. Hence, employee should extract some rent from a match in order to give unemployed workers an incentive to search. Therefore, the levels of the actual bargaining power can be ranked:

$$
\hat{\gamma}_{2}>\hat{\gamma}_{1}=0
$$

According to Equation (17), for any positive value of the bargaining power $\gamma$, implementing such an equilibrium requires:

$$
T_{m, 2}<1=T_{m, 1} .
$$

However, the position of $T_{m, 2}$ with respect to 0 and to the average tax rate $T_{2} / w_{2}$ is ambiguous. The tax schedule can be either progressive with $T_{m}>T / w$ or regressive and in this case marginal tax rates can be positive or negative.

Finally, since $\theta_{2}>\theta_{1}$ and $\omega_{2}>\omega_{1}$, one has

$$
T_{2}<T_{1}
$$

The level of tax required to decentralize the second-best optimum is lower than the firstbest one. This follows from two effects. First, employed workers' income has to be higher at the second best. Second, the inequality $\theta_{2}>\theta_{1}$ implies that the gross wage is lower at the second best.

Knowing how the second-best optimum can be decentralized, it is now possible to characterize the tax schedule in a more precise way. First, from $W S\left(\theta_{2}, \phi\left(\theta_{2}\right), e_{2}\right)=0$, it is immediately seen that $T_{m}$ increases with $\gamma$. Second, from the definition of $\hat{\gamma}$,

$$
T_{m, 2} \lessgtr 0 \Longleftrightarrow \gamma \lessgtr \hat{\gamma}_{2}
$$

\footnotetext{
${ }^{12}$ The case with linear preference is presented in Appendix 6 .
} 
Third, combining (10), (16) with the first equality in (9), it can be checked that for $r=0$ :

$$
\frac{1-T_{m}}{1-(T / w)}=\frac{1-\gamma}{\gamma} \frac{v(\omega)-v(z-d(e))}{\omega \cdot v^{\prime}(\omega)} \frac{m(\theta) \cdot y-c \cdot q}{c(q+e \cdot \alpha(\theta))}
$$

where $\left(1-T_{m}\right) /(1-(T / w))$ is the so-called coefficient of residual income progression CRIP (i.e. $d \ln (\omega) / d \ln (w))$. Consequently, for $\left.(\theta, w, e)=\left(\theta_{2}, \phi\left(\theta_{2}\right), e_{2}\right)\right)$, the CRIP would be equal to 1 if $\gamma=\widetilde{\gamma}$, with:

$$
\frac{\widetilde{\gamma}}{1-\widetilde{\gamma}}=\frac{v\left(\omega_{2}\right)-v\left(z_{2}-d\left(e_{2}\right)\right)}{\omega_{2} \cdot v^{\prime}\left(\omega_{2}\right)} \frac{m\left(\theta_{2}\right) \cdot y-c \cdot q}{c\left(q+e_{2} \cdot \alpha\left(\theta_{2}\right)\right)}
$$

For this particular value of $\gamma$, the tax schedule needed to decentralize the second-best optimum would actually be linear ${ }^{13}$. Otherwise, a non linear tax schedule is required.

Combining these elements, three cases are then possible. Before characterizing them, recall that $T_{2} / w_{2}$ cannot be negative because of the budget constraint, of the property $z_{2}>0$ and of our assumption that profits are nonnegative in equilibrium. First, if $\gamma>\widetilde{\gamma}$ and $\gamma>\hat{\gamma}_{2}$, then $T_{m, 2}>T_{2} / w_{2}>0$. Second, if $\hat{\gamma}_{2}<\gamma<\tilde{\gamma}$, then $T_{2} / w_{2}>T_{m, 2}>0$. Third, if $\gamma<\widetilde{\gamma}$ and $\gamma<\hat{\gamma}_{2}$, then $T_{m, 2}<0<T_{2} / w_{2}$. The fourth case, namely $\widetilde{\gamma}<\gamma<\hat{\gamma}_{2}$, can be ruled out since it would imply that $T_{2} / w_{2}<T_{m, 2}<0$.

The following proposition summarizes our results.

Proposition 5 To decentralize the second-best optimum, the actual bargaining power of the workers has to be equal to $\hat{\gamma}_{2}$, with $0<\hat{\gamma}_{2}<1$. When their bargaining power $\gamma$ is different from $\hat{\gamma}_{2}$, non linear taxation is typically necessary to decentralize the optimum. Then, the marginal tax rate is an increasing function of the bargaining power of the workers. When $\gamma<\hat{\gamma}_{2}$, the marginal tax rate is negative. Otherwise, it is nonnegative. There exists a threshold value of the workers' bargaining power, $\widetilde{\gamma}$, below which taxation is regressive and above which it is progressive. Finally, the level of taxes is lower than at the first-best optimum.

We are not able to analytically compare the first- and second-best optimal values of the unemployment rates, of tightness measured in gross units (i.e. $v / u$ ratios) and of the expected lifetime utilities of workers and of the representative firm-owner. An extensive numerical exercise has therefore been conducted in Lehmann and Van der Linden (2002). The following properties appear to be robust since they were systematically found in all (reported and unreported) simulations in this discussion paper.

First, the $v / u$ ratio is always higher and the unemployment rate $u$ is always lower at the first-best than at the second-best optimum. Recall that unemployed workers search less in the second best $\left(e_{2}<e_{1}\right)$ but that the labor market is then also more tight $\left(\theta_{2}>\theta_{1}\right)$.

\footnotetext{
${ }^{13}$ From Equation $(37), \widetilde{\gamma}$ lies in the $(0,1)$ interval.
} 
Due to these two opposite effects, the net impact on the $v / u$ ratio and the unemployment rate is theoretically unclear. In all the simulations where the tax schedule is allowed to be non linear, the increase in tightness $\theta$ is much less important than the decrease in search intensity $e_{2}<e_{1}$.

Second, the expected utility of the workers $(1-u) v(\omega)+u \cdot v(z-d(e))$ is higher at the second-best than at the first-best optimum. This is counter-intuitive for two reasons. First, it has been shown in proposition 4 that total net output is lower at the second best $\left(Y_{2}<Y_{1}\right)$. So there are less resources to be shared between workers and the firm owner. Second, it has been shown that unemployment insurance is imperfect at the second-best optimum. So, for a given level of average income, workers' expected utility should be lower at the second-best optimum compared to the first-best one. Since the expected utility of the workers is higher in the second best, the share of $Y$ accruing to them has to increase dramatically when search effort becomes unobservable and this increase has to outweigh the two previous effects. In other words, the unobservability of search intensity not only leads to imperfect unemployment insurance and lower search intensity (as emphasized in the literature on optimal unemployment insurance in partial search equilibrium frameworks) or to higher tightness (as shown in proposition 4). It also modifies the distribution of utility levels between workers and the firm owner in favor of the formers. Moreover, this shift is large enough to compensate the negative influences of the decrease in total net output and of the incompleteness of unemployment insurance on the expected utility of workers at the second best. The intuition behind this shift goes as follows. Proposition 5 has shown that the level of taxes is lower at the second-best than at the first-best optimum. Moreover, the unemployment rate is much higher at the second best, suggesting that unemployment benefits expenditures are probably higher too. Hence, the lump-sum transfer to the capital owner $(\chi$, with $\Pi=\chi$ when $r=0$ ) should be lower at the second-best optimum.

\section{Conclusion}

Since the paper of Hosios (1990), the condition under which a search-matching economy is efficient is well-known when agents have linear preferences. If the bargaining power of the workers is appropriate, a laissez-faire economy is then recommended. Otherwise, other instruments are needed to decentralize the optimum. Income taxation is a natural candidate (see Boone and Bovenberg (2001a)). The risk-neutrality assumption is convenient but counter-factual. Furthermore, it implies that economists do not take part to the debate about inequalities in societies with unemployment. For these very reasons, this paper has revisited the normative properties of a search-matching economy when workers 
have concave utility functions. For this purpose, we have developed a general equilibrium framework with homogeneous agents, endogenous job-search and wage bargaining.

We have contrasted a first-best optimum where the State can perfectly monitor unemployed workers' search intensity and a second-best optimum with moral hazard. In the first-best setting, efficiency can be achieved independently of the redistributive issues and the State can perfectly insure workers against the unemployment risk. The implementation of the first best requires that workers can in no way extract a rent from the match. If their bargaining power is positive, a $100 \%$ marginal tax rate is necessary to decentralize the optimum.

When unemployed people freely choose their level of search (the second-best case), this paper has shown that search intensity and total net output should optimally be lower and that tightness (measured in efficiency units) should be higher than in the first-best optimum. It has also been shown that in comparison with the decentralization of the first-best allocation, the implementation of the second-best optimum requires a lower marginal tax rate, a lower level of taxes on labor and typically a lower level of unemployment benefits. power. Whether, income taxation should be progressive or regressive heavily depends on the value of the workers' bargaining power. For sufficiently low values of the latter, the marginal tax rate could even become negative in order to provide appropriate incentives to search and to create vacancies. Conversely, when workers have a strong bargaining power, taxation could become very progressive (as it is illustrated in a companion paper; see Lehmann and Van der Linden (2002)). This paper therefore sheds new light on the debate about the pros and cons of progressive income taxation. Except for one particular level of workers' bargaining power, a non proportional tax schedule is a necessary instrument to decentralize the second-best optimum. When agents are homogeneous, a tax schedule with a constant marginal tax rate and an intercept would do the trick. With heterogeneous workers, a more complex non-linear tax schedule would be unavoidable to decentralize the optima.

This paper could be extended in different ways. First, the introduction has cited several papers that have been concerned with the optimal profile of unemployment benefits over the unemployment spell rather than a single level of unemployment benefits. Introducing, say, two levels of unemployment benefits in our analytical framework would introduce additional instruments to share risks and to redistribute income between firms and workers. Second, with respect to the monitoring of search effort, we have only considered two polar cases (namely job-search decisions were either perfectly observed or not observed at all). However, in a more realistic framework, the State can imperfectly observe search behavior and therefore introduce an imperfect sanction mechanism, just as in Boone and van Ours 
(2000), or Boone et al (2001). Third, we have assumed an homogenous labor force. However, workers actually have different levels of productivity in employment (as in the optimal taxation literature following Mirrlees (1971) and in Boone and Bovenberg (2001b)) and the disutility of search can be heterogeneous too. Introducing such features would clearly enrich the analysis but are expected to complicate the model a lot.

\section{References}

[1] Baily M.N., 1977, Unemployment insurance as insurance for workers, Industrial and Labor Relations Review, 30, pp. 495-504.

[2] Boadway R. and K. Cuff, 1999, Monitoring job search as an instrument for targeting transfers, International Tax and Public Finance, 6, pp. 317-337.

[3] Boone J. and L.A. Bovenberg, 2001a, Optimal labour taxation and search, Centre for Economic Policy Research, Discussion paper 3002, forthcoming in the Journal of Public Economics.

[4] Boone J. and L.A. Bovenberg, 2001b, Unemployment vs. in-work benefits with search unemployment and observable abilities, Centre for Economic Policy Research, Discussion paper 3043.

[5] Boone, J and R. de Mooij, 2000, Tax policy in a model of search with training, CESifo working paper series 232, Munich.

[6] Boone, J., Fredriksson, P., Holmlund, B. and J. van Ours, 2001, Optimal Unemployment Insurance with Monitoring and Sanctions, Discussion Paper 2001-85 Centre for Economic Research, Tilburg University.

[7] Boone, J. and J. van Ours, 2000, Modeling financial incentives to get unemployed back to work, Discussion Paper 2000-02 CentER for Economic Research, Tilburg University.

[8] Cahuc, P. and E. Lehmann, 2000, Should unemployment benefits decrease with the unemployment spell ? Journal of Public Economics, 77, pp. 135-143

[9] Fredriksson, P. and B. Holmlund, 2001, Optimal unemployment insurance in search equilibrium, Journal of Labor Economics, 19, pp. 370-399.

[10] Fuest, C. and B. Huber, 2000, Is tax progression really good for employment ? A model with endogenous hours of work, Labour Economics, 7, pp. 79-93.

[11] Hansen C. T., 1999, Lower tax progression, longer hours and higher wages, Scandinavian Journal of Economics, 101, pp. 49-65.

[12] Holmlund B., 1998, Unemployment insurance in theory and practice, Scandinavian Journal of Economics, 100(1), pp. 113-141.

[13] Holmlund B. and Lundborg 1989, Unemployment insurance schemes for reducing the natural rate of unemployment, Journal of Public Economics, 38, pp. 1-15.

[14] Holmlund, B. and A. S. Kolm, 1995, Progressive taxation, wage setting and unemployment: theory and evidence, Working paper series 1995:15, Uppsala University.

[15] Hopenhayn, H. and Nicolini, J. P., 1997, Optimal Unemployment Insurance, Journal of Political Economy, 105(2), pp. 412-438.

[16] Hosios, A., 1990, On the efficiency of matching and related models of search and unemployment, Review of Economic Studies, 57, pp. 279-298. 
[17] Layard, R., Nickell, S. and Jackman, R., 1991, Unemployment: Macroeconomic performance and the labor market, Oxford University Press, Oxford.

[18] Lehmann, E. and Van der Linden, B., 2002, Optimal unemployment benefits and non-linear income taxation in a matching model with wage bargaining, Cahiers de la Maison des Sciences Economiques 2002.01, EUREQua, Université Paris 1. http://www.univ-paris1.fr/MSE/CahiersMSE

[19] Lockwood, B. and Manning, A., 1993, Wage setting and the Tax system, Theory and evidence for the United Kingdom, Journal of Public Economics, 52, pp. 1-29.

[20] Malcomson J. and Sator, N., 1987, Tax push inflation in a unionized labour market, European Economic Review, 31, pp. 1581-1596.

[21] Mirrlees, J., 1971, An exploration in a Theory of Optimal Income Taxation, Review of Economic Studies, 38, pp. 175-208.

[22] Moen, E. R., 1997, Competitive search equilibrium, Journal of Political Economy, 105, pp. 385-411.

[23] Pissarides, C. A., 1998, The Impact of employment tax cuts on unemployment and wages: The role of Unemployment Benefits and Tax structure, European Economic Review, 42, pp. 155-183.

[24] Pissarides, C. A., 2000, Equilibrium Unemployment Theory, $2^{\text {nd }}$ edition, MIT Press.

[25] Saez, E, 2001, Optimal income transfer programs: Intensive versus Extensive labor supply responses, Forthcoming in Quarterly Journal of Economics.

[26] Shavell, S. and L. Weiss, 1979, The optimal payment of unemployment insurance benefits over time, Journal of Political Economy, 87(6), pp. 1347-1362.

[27] Sorensen, P. B., Optimal tax progressivity in imperfect labour markets, Labour economics, 6, pp. 435-452.

\section{Appendix}

\section{Appendix 1: Partial Derivatives}

From

$$
S(\theta, w, e) \equiv \alpha(\theta)(v(w-T)-v(z-d(e)))-d^{\prime}(e) \cdot v^{\prime}(z-d(e))(r+q+e \cdot \alpha(\theta))=0
$$

one has:

$$
\begin{aligned}
S_{e}^{\prime}= & \alpha(\theta) \cdot d^{\prime}(e) \cdot v^{\prime}(z-d(e))-\alpha(\theta) \cdot d^{\prime}(e) \cdot v^{\prime}(z-d(e))+ \\
& \left(-d^{\prime \prime}(e) \cdot v^{\prime}(z-d(e))+\left[d^{\prime}(e)\right]^{2} v^{\prime \prime}(z-d(e))\right)(r+q+e \cdot \alpha(\theta)) \\
S_{w}^{\prime}= & \alpha(\theta) \cdot v^{\prime}(w-T)>0 \\
S_{\theta}^{\prime}= & \alpha^{\prime}(\theta)\left[v(w-T)-v(z-d(e))-e \cdot d^{\prime}(e) \cdot v^{\prime}(z-d(e))\right]
\end{aligned}
$$

Since, $v^{\prime \prime}()<$.0 and $d^{\prime \prime}() \geq$.0 , it is easily checked that $S_{e}^{\prime}<0$. Equation $S(., .,)=$.0 , can be rearranged to yield:

$$
v(w-T)-v(z-d(e))=\frac{r+q+e \cdot \alpha(\theta)}{\alpha(\theta)} d^{\prime}(e) \cdot v^{\prime}(z-d(e))
$$


Therefore,

$$
S_{\theta}^{\prime}=\frac{\alpha^{\prime}(\theta)}{\alpha(\theta)}(r+q) \cdot d^{\prime}(e) \cdot v^{\prime}(z-d(e))>0
$$

Finally, one has

$$
\begin{aligned}
S_{T_{m}}^{\prime} & =0 \\
S_{T}^{\prime} & =-\alpha(\theta) \cdot v^{\prime}(w-T(w))=-S_{w}^{\prime}<0 \\
S_{z}^{\prime} & =-\alpha(\theta) \cdot v^{\prime}(z-d(e))-d^{\prime}(e)(r+q+e \cdot \alpha(\theta)) v^{\prime \prime}(z-d(e))
\end{aligned}
$$

From:

$W S(\theta, w, e) \equiv v(w-T)-v(z-d(e))-\frac{c \cdot \gamma}{1-\gamma}\left(1-T_{m}\right) \frac{r+q+e \cdot \alpha(\theta)}{m(\theta)} \cdot v^{\prime}(w-T)=0$

the following partial derivatives can be computed:

$$
\begin{aligned}
W S_{\theta}^{\prime} & =-\frac{c \cdot \gamma}{1-\gamma} \cdot \frac{1-T_{m}}{m(\theta)}\left(e \cdot \alpha^{\prime}(\theta)-\frac{m^{\prime}(\theta)(r+q+e \cdot \alpha(\theta))}{m(\theta)}\right)<0 \\
W S_{w}^{\prime} & =v^{\prime}(w-T)-\frac{c \cdot \gamma}{1-\gamma}\left(1-T_{m}\right) \frac{r+q+e \cdot \alpha(\theta)}{m(\theta)} \cdot v^{\prime \prime}(w-T)>0 \\
W S_{e}^{\prime} & =d^{\prime}(e) \cdot v^{\prime}(z-d(e))-\frac{c \cdot \gamma}{1-\gamma}\left(1-T_{m}\right) \frac{\alpha(\theta)}{m(\theta)} \cdot v^{\prime}(w-T)
\end{aligned}
$$

After some manipulation, $W S(., .,)=$.0 becomes:

$$
\frac{c \cdot \gamma}{1-\gamma} \cdot \frac{\left(1-T_{m}\right) \cdot v^{\prime}(w-T)}{m(\theta)}=\frac{v(w-T)-v(z-d(e))}{r+q+e \cdot \alpha(\theta)}
$$

Taking this equality into account leads to:

$$
W S_{e}^{\prime}=d^{\prime}(e) \cdot v^{\prime}(z-d(e))-\alpha(\theta) \frac{v(w-T)-v(z-d(e))}{r+q+e \cdot \alpha(\theta)}=-\frac{S(\theta, w, e)}{r+q+e \cdot \alpha(\theta)}
$$

Hence, $W S_{e}^{\prime}$ is equal to zero in equilibrium. Finally, one has:

$$
\begin{aligned}
W S_{T}^{\prime} & =-v^{\prime}(w-T)+\frac{c \cdot \gamma}{1-\gamma}\left(1-T_{m}\right) \frac{r+q+e \cdot \alpha(\theta)}{m(\theta)} \cdot v^{\prime \prime}(w-T)<0 \\
W S_{T_{m}}^{\prime} & =\frac{c \cdot \gamma}{1-\gamma} \frac{r+q+e \cdot \alpha(\theta)}{m(\theta)} \cdot v^{\prime}(w-T)>0 \\
W S_{z}^{\prime} & =-v^{\prime}(z-d(e))<0
\end{aligned}
$$

\section{Appendix 2: Unicity of the equilibrium, comparative statics and dynamic properties}

First we show that the system $\mathbb{S}(\theta, e)=\mathbb{W}(\theta, e)=0$ has at most one solution. Since $\mathbb{S}_{e}^{\prime}(\theta, e)<0$, for any $\theta$, the equation $\mathbb{S}(\theta, e)=0$ admits at most one solution. Call this solution $\mathbb{E}(\theta)$ if it exists. The implicit function theorem insures that function $\mathbb{E}(\theta)$ is continuous and differentiable wherever it is defined. Now, let $\mathcal{W}(\theta) \equiv \mathbb{W}(\theta, \mathbb{E}(\theta))$. An 
equilibrium necessarily solves $\mathcal{W}(\theta)=0$. Differentiating function $\mathcal{W}\left(\right.$.) yields $\mathcal{W}^{\prime}(\theta)=$ $\mathbb{W}_{\theta}^{\prime}(\theta, \mathbb{E}(\theta))+\mathbb{E}^{\prime}(\theta) \cdot \mathbb{W}_{e}^{\prime}(\theta, \mathbb{E}(\theta))$. Since $\mathbb{E}(\theta)$ solves $\mathbb{S}(\theta, \mathbb{E}(\theta))=0$, one has:

$$
\mathbb{W}_{e}^{\prime}(\theta, \mathbb{E}(\theta))=-\mathbb{S}(\theta, \mathbb{E}(\theta)) /(r+q+\mathbb{E}(\theta) \cdot \theta)=0
$$

Hence, $\mathcal{W}^{\prime}(\theta)=\mathbb{W}_{\theta}^{\prime}(\theta, \mathbb{E}(\theta))<0$. So equation $\mathcal{W}(\theta)=0$ admits at most one solution. The equilibrium, if any, is therefore unique.

Second, we look at the comparative statics of the equilibrium. Differentiating $\mathbb{S}(\theta, e)=$ $\mathbb{W}(\theta, e)=0$ yields:

$$
\left(\begin{array}{ll}
\mathbb{W}_{\theta}^{\prime} & \mathbb{W}_{e}^{\prime} \\
\mathbb{S}_{\theta}^{\prime} & \mathbb{S}_{e}^{\prime}
\end{array}\right)\left(\begin{array}{c}
d \theta \\
d e
\end{array}\right)=-\left(\begin{array}{lll}
\mathbb{W}_{z}^{\prime} & \mathbb{W}_{T}^{\prime} & \mathbb{W}_{T_{m}}^{\prime} \\
\mathbb{S}_{z}^{\prime} & \mathbb{S}_{T}^{\prime} & \mathbb{S}_{T_{m}}^{\prime}
\end{array}\right)\left(\begin{array}{c}
d z \\
d T \\
d T_{m}
\end{array}\right)
$$

Since around the equilibrium $\mathbb{W}_{e}^{\prime}=0$, one has:

$$
\left(\begin{array}{c}
d \theta \\
d e
\end{array}\right)=\left(\begin{array}{cc}
-\frac{1}{\mathbb{W}_{\theta}^{\prime}} & 0 \\
\mathbb{S}_{\theta}^{\prime} & -\frac{1}{\mathbb{S}_{e}^{\prime} \cdot \mathbb{W}_{\theta}^{\prime}}
\end{array}\right)\left(\begin{array}{lll}
\mathbb{W}_{z}^{\prime} \cdot d z & \mathbb{W}_{T}^{\prime} \cdot d T & \mathbb{W}_{T_{m}}^{\prime} \cdot d T_{m} \\
\mathbb{S}_{z}^{\prime} \cdot d z & \mathbb{S}_{T}^{\prime} \cdot d T & \mathbb{S}_{T_{m}}^{\prime} \cdot d T_{m}
\end{array}\right)
$$

Hence:

$$
d \theta=-\frac{\mathbb{W}_{z}^{\prime}}{\mathbb{W}_{\theta}^{\prime}} d z-\frac{\mathbb{W}_{T}^{\prime}}{\mathbb{W}_{\theta}^{\prime}} d T-\frac{\mathbb{W}_{T_{m}}^{\prime}}{\mathbb{W}_{\theta}^{\prime}} d T_{m}
$$

Since $\mathbb{W}_{\theta}^{\prime}<0, \mathbb{W}_{z}^{\prime}<0, \mathbb{W}_{T}^{\prime}<0, \mathbb{W}_{T_{m}}^{\prime}>0$ one has $d \theta / d z<0, d \theta / d T<0$ and $d \theta / d T_{m}>0$. Moreover,

$$
\begin{aligned}
d e= & \frac{\mathbb{S}_{\theta}^{\prime} \cdot \mathbb{W}_{z}^{\prime}-\mathbb{W}_{\theta}^{\prime} \cdot \mathbb{S}_{z}^{\prime}}{\mathbb{S}_{e}^{\prime} \cdot \mathbb{W}_{\theta}^{\prime}} d z+\frac{\mathbb{S}_{\theta}^{\prime} \cdot \mathbb{W}_{T}^{\prime}-\mathbb{W}_{\theta}^{\prime} \cdot \mathbb{S}_{T}^{\prime}}{\mathbb{S}_{e}^{\prime} \cdot \mathbb{W}_{\theta}^{\prime}} d T+\frac{\mathbb{S}_{\theta}^{\prime} \cdot \mathbb{W}_{T_{m}}^{\prime}-\mathbb{W}_{\theta}^{\prime} \cdot \mathbb{S}_{T_{m}}^{\prime}}{\mathbb{S}_{e}^{\prime} \cdot \mathbb{W}_{\theta}^{\prime}} d T_{m} \\
\mathbb{S}_{\theta}^{\prime} & =S_{\theta}^{\prime}+\phi^{\prime}(\theta) \cdot S_{w}^{\prime} \\
& =\frac{\alpha^{\prime}(\theta)}{\alpha(\theta)}(r+q) \cdot d^{\prime}(e) \cdot v^{\prime}(z-d(e))+\frac{c(r+q)}{m(\theta)} \cdot \frac{m^{\prime}(\theta)}{m(\theta)} \alpha(\theta) v^{\prime}(w-T)
\end{aligned}
$$

By equations (13), (9) and (16), one has

$$
\begin{aligned}
\mathbb{S}_{\theta}^{\prime} & =(r+q)\left(V-V^{u}\right)\left\{\alpha^{\prime}(\theta)+\theta m^{\prime}(\theta) \frac{1-\gamma}{\gamma\left(1-T_{m}\right)}\right\} \\
& =(r+q)\left(V-V^{u}\right) m(\theta)\left\{1+\frac{\theta m^{\prime}(\theta)}{m(\theta)}\left(1+\frac{1-\gamma}{\gamma\left(1-T_{m}\right)}\right)\right\}
\end{aligned}
$$

Recall that $\hat{\gamma} /(1-\hat{\gamma})=\gamma\left(1-T_{m}\right) /(1-\gamma)$. Then:

$$
\mathbb{S}_{\theta}^{\prime}=(r+q)\left(V-V^{u}\right) m(\theta)\left\{1+\frac{\theta m^{\prime}(\theta)}{m(\theta)} \cdot \frac{1}{\hat{\gamma}}\right\}
$$

So, under the Hosios condition, $\hat{\gamma}=-\frac{\theta m^{\prime}(\theta)}{m(\theta)}$, one gets $\mathbb{S}_{\theta}^{\prime}=0$ around the equilibrium, and:

$$
d e=-\frac{\mathbb{S}_{z}^{\prime}}{\mathbb{W}_{\theta}^{\prime}} d z-\frac{\mathbb{S}_{T}^{\prime}}{\mathbb{W}_{\theta}^{\prime}} d T-\frac{\mathbb{S}_{T_{m}}^{\prime}}{\mathbb{S}_{e}^{\prime}} d T_{m}
$$


Hence, one has $\frac{d e}{d T}<0, \frac{d e}{d T_{m}}=0$ but $\frac{d e}{d z}$ remains ambiguous. However, whenever $\hat{\gamma} \neq$ $-\frac{\theta m^{\prime}(\theta)}{m(\theta)}, \mathbb{S}_{\theta}^{\prime}$ has an ambiguous sign, so the marginal effect of $z, T, T_{m}$ on $e$ cannot be signed.

Third, consider the dynamic properties. Along the transitional dynamics, given $z, T$ and $T_{m}$, equations (9), (13) and (16) gives $\theta, w$ and $e$ as a function of $J$ and $V-V^{u}$ according to:

$$
\begin{aligned}
\theta & =(m)^{-1}\left(\frac{c}{J}\right) \quad e=\left(d^{\prime}(e) \cdot v^{\prime}(z-d(e))\right)^{-1}\left(\alpha(\theta)\left(V-V^{u}\right)\right) \\
w & =T+\left(v^{\prime}\right)^{-1}\left(\frac{1-\gamma}{\gamma} \cdot \frac{V-V^{u}}{J}\right)
\end{aligned}
$$

Hence, the dynamics of $(\theta, w, e)$ depends only on the evolution of $J$ and $V-V^{u}$. According to equations $(7),(11)$ and (12), one has

$$
\begin{aligned}
\dot{J}= & (r+q) J-y+w\left(J, V-V^{u}\right) \\
V-V^{u}= & {\left[r+q+e\left(J, V-V^{u}\right) \cdot \alpha\left(\theta\left(J, V-V^{u}\right)\right)\right]\left(V-V^{u}\right) } \\
& -v\left(w\left(J, V-V^{u}\right)-T\right)+v\left(z-d\left(e\left(J, V-V^{u}\right)\right)\right)
\end{aligned}
$$

So, $X=\left(J, V-V^{u}\right)$ is a vector of state variables that evolves as a function of itself only. Denote $D$ the dynamics so $\dot{X}=D(X)$. A steady state equilibrium solves $D=0$. Since all the variables in vector $X$ are forward looking, two cases might appear regarding to the eigenvalues of the Jacobian of $D$ in the neighborhood of the steady state. If all the eigenvalues have a strictly positive real part, the transitional dynamics is unique and the state variables instantaneously reach their steady state value. Otherwise, there is a multiplicity of transitional dynamics, one of them being the instantaneous jump of the state variable to their steady-state value. Applying a selection criteria based on simplicity, one can think that this dynamics would be the more realistic. This is exactly what we assume. Hence, we consider that $X$ and therefore $\theta, e$ and $w$ are always at their steadystate values. The adjustment of the unemployment rate is then determined by equation $\dot{u}=q(1-u)-e \cdot \alpha(\theta)$ where $e$ and $\theta$ always are at their steady state values.

\section{Appendix 3 The Social Welfare Criteria}

The social welfare criteria $\Omega=(1-u) V+u \cdot V^{u}+\eta \cdot \mathbb{P}$ can be differentiated with respect to time. This derivative can then be substracted from $r \cdot \Omega$ to yield :

$$
\begin{aligned}
r \cdot \Omega-\dot{\Omega}= & (1-u)(r \cdot V-\dot{V})+u \cdot\left(r \cdot V^{u}-\dot{V}^{u}\right)+\eta(r \cdot \mathbb{P}-\dot{\mathbb{P}})+\dot{u}\left(V-V^{u}\right) \\
= & (1-u) v(\omega)+u \cdot v(z-d(e))+\eta(r \cdot \mathbb{P}-\dot{\mathbb{P}}) \\
& +\left(V-V^{u}\right)(e \cdot \alpha(\theta) \cdot u-q(1-u)+\dot{u})
\end{aligned}
$$

by definition of $V$ and $V^{u}$. Moreover, according to (6), one has:

$$
\dot{\mathbb{P}}_{t}=-\Pi_{t}+\int_{t}^{+\infty} r \cdot e^{-r(\tau-t)} \cdot \Pi_{\tau} \cdot d \tau=-\Pi_{t}+r \cdot \mathbb{P}_{t}
$$

Since $\dot{u}=q(1-u)-e \cdot \alpha(\theta) \cdot u$ and $r \cdot \mathbb{P}-\dot{\mathbb{P}}=\Pi$ one concludes that:

$$
r \cdot \Omega-\dot{\Omega}=(1-u) v(\omega)+u \cdot v(z-d(e))+\eta \cdot \Pi
$$

So,

$$
\Omega=\int e^{-r t}\{(1-u) v(\omega)+u \cdot v(z-d(e))+\eta \cdot \Pi\} \cdot d t
$$




\section{Appendix 4: Characterization of the first-best optimum}

Since $F(\theta, e)=\alpha^{\prime}(\theta)\left(d^{\prime}(e)+c \cdot \theta\right)-c \cdot \alpha(\theta)$, the partial derivatives of $F$ have unambiguous signs:

$$
\begin{aligned}
& F_{\theta}^{\prime}=\alpha^{\prime \prime}(\theta)\left(d^{\prime}(e)+c \cdot \theta\right)+c \cdot \alpha^{\prime}(\theta)-c \cdot \alpha^{\prime}(\theta)<0 \\
& F_{e}^{\prime}=\alpha^{\prime}(\theta) \cdot d^{\prime \prime}(e)>0
\end{aligned}
$$

$G(\theta, e)$ can be rewritten as $\alpha(\theta)(y+d(e))-c \cdot \theta \cdot q-d^{\prime}(e)(e \cdot \alpha(\theta)+q)$. Then,

$$
\begin{aligned}
& G_{e}^{\prime}=-d^{\prime \prime}(e)(e \cdot \alpha(\theta)+q)<0 \\
& G_{\theta}^{\prime}=\alpha^{\prime}(\theta)\left(y+d(e)-e \cdot d^{\prime}(e)\right)-c \cdot q
\end{aligned}
$$

However, along $G(\theta, e)=0$, one has:

$$
y+d(e)=\frac{c \cdot \theta \cdot q+d^{\prime}(e)(e \cdot \alpha(\theta)+q)}{\alpha(\theta)}=\frac{q}{\alpha(\theta)} \cdot\left(c \cdot \theta+d^{\prime}(e)\right)+e \cdot d^{\prime}(e)
$$

Therefore,

$$
\begin{aligned}
G_{\theta}^{\prime} & =\alpha^{\prime}(\theta) \cdot \frac{q}{\alpha(\theta)} \cdot\left(c \cdot \theta+d^{\prime}(e)\right)-c \cdot q \\
& =q \cdot \alpha^{\prime}(\theta)\left(\frac{c \cdot \theta+d^{\prime}(e)}{\alpha(\theta)}-\frac{c}{\alpha^{\prime}(\theta)}\right) \\
& =\frac{q}{\alpha(\theta)}\left(\alpha^{\prime}(\theta)\left(c \cdot \theta+d^{\prime}(e)\right)-c \cdot \alpha(\theta)\right)=\frac{q}{\alpha(\theta)} F(\theta, e)
\end{aligned}
$$

Finally, differentiating $H(\theta, e)=\alpha^{\prime}(\theta)(y+d(e)+e \cdot c \cdot \theta)-c(e \cdot \alpha(\theta)+q)$ yields:

$$
\begin{aligned}
& H_{\theta}^{\prime}=\alpha^{\prime \prime}(\theta)(y+d(e)+e \cdot c \cdot \theta)+e \cdot c \cdot \alpha^{\prime}(\theta)-e \cdot c \cdot \alpha^{\prime}(\theta)<0 \\
& H_{e}^{\prime}=\alpha^{\prime}(\theta)\left(d^{\prime}(e)+c \cdot \theta\right)-c \cdot \alpha(\theta)=F(\theta, e)
\end{aligned}
$$

\section{Appendix 5: The second-best optimum with risk averse workers}

Let us first show $\psi_{2}>0$. From first-order condition (33),

$$
\psi_{2}=\frac{u_{2}\left[d^{\prime}\left(e_{2}\right) \cdot v^{\prime}\left(z_{2}-d\left(e_{2}\right)\right)+\eta \cdot c \cdot \theta_{2}-\delta_{2} \cdot \alpha\left(\theta_{2}\right)\right]}{\left\{-d^{\prime \prime}\left(e_{2}\right) \cdot v^{\prime}\left(z_{2}-d\left(e_{2}\right)\right)+\left(d^{\prime}\left(e_{2}\right)\right)^{2} \cdot v^{\prime \prime}\left(z_{2}-d\left(e_{2}\right)\right)\right\}\left(q+e_{2} \cdot \alpha\left(\theta_{2}\right)\right)}
$$

The denominator of the last expression is clearly negative. Therefore, its numerator has to be non positive in order to guarantee that $\psi_{2} \geq 0$. To show that this numerator is negative, one has to extract $\delta_{2} \cdot \alpha\left(\theta_{2}\right)$ from condition (34). Taking (30) into account, this yields:

$$
\delta_{2} \cdot \alpha\left(\theta_{2}\right)=v^{\prime}\left(z_{2}-d\left(e_{2}\right)\right) \cdot d^{\prime}\left(e_{2}\right)+\eta \frac{\alpha\left(\theta_{2}\right)}{q_{2}+e_{2} \cdot \alpha\left(\theta_{2}\right)}\left(y-\omega_{2}+z_{2}+c \cdot e_{2} \cdot \theta_{2}\right)
$$

Substituting this in the numerator of the right hand side of $(38), \psi_{2} \geq 0$ is equivalent to:

$$
c \cdot \theta_{2} \leq \frac{\alpha\left(\theta_{2}\right)}{q_{2}+e_{2} \cdot \alpha\left(\theta_{2}\right)}\left(y-\omega_{2}+z_{2}+c \cdot e_{2} \cdot \theta_{2}\right)
$$


After some simplifications, using (1), $\psi_{2} \geq 0$ is equivalent to

$$
c \cdot e_{2} \cdot \theta_{2} \cdot u_{2} \leq\left(1-u_{2}\right)\left(y-\omega_{2}+z_{2}\right)
$$

or:

$$
\left(1-u_{2}\right)\left(\omega_{2}-z_{2}\right) \leq\left(1-u_{2}\right) y-c \cdot v_{2}
$$

But, by (4)

$$
\left(1-u_{2}\right) \omega_{2}+u_{2} \cdot z_{2}+\Pi_{2}=\left(1-u_{2}\right) y-c \cdot v_{2}
$$

So $\psi_{2} \geq 0$ is equivalent to:

$$
\begin{aligned}
\left(1-u_{2}\right)\left(\omega_{2}-z_{2}\right) & \leq\left(1-u_{2}\right) \omega_{2}+u_{2} \cdot z_{2}+\Pi_{2} \\
-\left(1-u_{2}\right) z_{2} & \leq u_{2} \cdot z_{2}+\Pi_{2} \\
-z_{2} & \leq \Pi_{2}
\end{aligned}
$$

This condition is satisfied since, by assumption $\Pi_{2}$ and $z_{2}$ are nonnegative.

Hence, when workers are risk averse, the incentive constraint (30) implies that $\omega_{2}>$ $z_{2}-d\left(e_{2}\right)$, thereby $v^{\prime}\left(\omega_{2}\right)<v^{\prime}\left(z_{2}-d\left(e_{2}\right)\right)$. Therefore, $\psi_{2} \neq 0$ according to (31) and (32). Consequently, $\psi_{2}>0$.

It will now be shown that one has $G\left(\theta_{2}, e_{2}\right)>0$ at the second-best optimum. Dividing first-order condition (34) by $\eta$, adding $d\left(e_{2}\right)$ on both sides and rearranging yields:

$$
y+d\left(e_{2}\right)+c \cdot e_{2} \cdot \theta_{2}=\frac{\delta_{2}}{\eta}\left(e_{2} \cdot \alpha\left(\theta_{2}\right)+q\right)-\frac{v\left(\omega_{2}\right)-v\left(z_{2}-d\left(e_{2}\right)\right)}{\eta_{2}}+\omega_{2}-z_{2}+d\left(e_{2}\right)
$$

Multiplying both sides by $\alpha\left(\theta_{2}\right)$ yields:

$$
\begin{aligned}
& \alpha\left(\theta_{2}\right)\left(y+d\left(e_{2}\right)+c \cdot e_{2} \cdot \theta_{2}\right)=\frac{\delta_{2} \cdot \alpha\left(\theta_{2}\right)}{\eta}\left(e_{2} \cdot \alpha\left(\theta_{2}\right)+q\right) \\
& -\frac{\alpha\left(\theta_{2}\right)\left[v\left(\omega_{2}\right)-v\left(z_{2}-d\left(e_{2}\right)\right)\right]}{\eta}+\alpha\left(\theta_{2}\right)\left(\omega_{2}-z_{2}+d\left(e_{2}\right)\right)
\end{aligned}
$$

Taking the incentive constraint (30) into account, the previous equality can be rewritten in the following way:

$$
\begin{aligned}
\alpha\left(\theta_{2}\right)\left(y+d\left(e_{2}\right)+c \cdot e_{2} \cdot \theta_{2}\right)= & \frac{e_{2} \cdot \alpha\left(\theta_{2}\right)+q}{\eta}\left[\delta_{2} \cdot \alpha\left(\theta_{2}\right)-d^{\prime}\left(e_{2}\right) \cdot v^{\prime}\left(z_{2}-d\left(e_{2}\right)\right)\right] \\
& +\alpha\left(\theta_{2}\right)\left(\omega_{2}-z_{2}+d\left(e_{2}\right)\right)
\end{aligned}
$$

The right-hand side of the last equality can be substituted in the definition of function $G$ evaluated at $\left(\theta_{2}, e_{2}\right)$. After some manipulations, this yields:

$$
\begin{aligned}
G\left(\theta_{2}, e_{2}\right)= & \frac{e_{2} \cdot \alpha\left(\theta_{2}\right)+q}{\eta}\left[\delta_{2} \cdot \alpha\left(\theta_{2}\right)-d^{\prime}\left(e_{2}\right) \cdot v^{\prime}\left(z_{2}-d\left(e_{2}\right)\right)-c \cdot \theta_{2} \cdot \eta\right] \\
& +\alpha\left(\theta_{2}\right)\left(\omega_{2}-z_{2}+d\left(e_{2}\right)\right)-\left(e_{2} \cdot \alpha\left(\theta_{2}\right)+q\right) d^{\prime}\left(e_{2}\right)
\end{aligned}
$$

Using once again the incentive constraint, $G\left(\theta_{2}, e_{2}\right)$ can be restated as:

$$
\begin{aligned}
G\left(\theta_{2}, e_{2}\right)= & \frac{e_{2} \cdot \alpha\left(\theta_{2}\right)+q}{\eta}\left[\delta_{2} \cdot \alpha\left(\theta_{2}\right)-d^{\prime}\left(e_{2}\right) \cdot v^{\prime}\left(z_{2}-d\left(e_{2}\right)\right)-c \cdot \theta_{2} \cdot \eta\right] \\
& +\frac{\alpha\left(\theta_{2}\right)}{v^{\prime}\left(z_{2}-d\left(e_{2}\right)\right)}\left[v^{\prime}\left(z_{2}-d\left(e_{2}\right)\right) \cdot\left(\omega_{2}-z_{2}+d\left(e_{2}\right)\right)-v\left(\omega_{2}\right)+v\left(z_{2}-d\left(e_{2}\right)\right)\right]
\end{aligned}
$$


However, the first-order condition (33) insures that:

$$
\begin{aligned}
& \delta_{2} \cdot \alpha\left(\theta_{2}\right)-d^{\prime}\left(e_{2}\right) \cdot v^{\prime}\left(z_{2}-d\left(e_{2}\right)\right)-c \cdot \theta_{2} \cdot \eta \\
= & \frac{\psi_{2}}{u_{2}}\left[d^{\prime \prime}\left(e_{2}\right) \cdot v^{\prime}\left(z_{2}-d\left(e_{2}\right)\right)-\left(d^{\prime}\left(e_{2}\right)\right)^{2} \cdot v^{\prime \prime}\left(z_{2}-d\left(e_{2}\right)\right)\right]\left(q+e_{2} \cdot \alpha\left(\theta_{2}\right)\right)>0
\end{aligned}
$$

So, the first term on the right hand side of (40) is positive. In addition, the concavity of $v($.$) implies that :$

$$
v\left(\omega_{2}\right)-v\left(z_{2}-d\left(e_{2}\right)\right)<v^{\prime}\left(z_{2}-d\left(e_{2}\right)\right) \cdot\left(\omega_{2}-z_{2}+d\left(e_{2}\right)\right)
$$

by which the second term on the right hand side of (40) is positive too. Therefore, function $G$ evaluated at the second-best optimum is positive while the same function was zero and reached a maximum evaluated at the first-best optimum. So, $e_{2}<e_{1}$.

Next, it will be shown that $H(\theta, e)<0$ at the second-best optimum. The first-order condition (35) together with the incentive constraint (30) gives:

$$
c \cdot e_{2} \cdot \eta \cdot u_{2}=\delta_{2} \cdot \alpha^{\prime}\left(\theta_{2}\right) \cdot e_{2} \cdot u_{2}+\psi_{2} \cdot \alpha^{\prime}\left(\theta_{2}\right) \cdot \frac{q}{\alpha\left(\theta_{2}\right)} \cdot v^{\prime}\left(z_{2}-d\left(e_{2}\right)\right) \cdot d^{\prime}\left(e_{2}\right)
$$

Substituting the flow equilibrium (1) yields:

$$
c=\alpha^{\prime}\left(\theta_{2}\right)\left\{\frac{\delta_{2}}{\eta}+\frac{\psi_{2}}{\eta} \cdot \frac{1}{1-u_{2}} \cdot v^{\prime}\left(z_{2}-d\left(e_{2}\right)\right) \cdot d^{\prime}\left(e_{2}\right)\right\}
$$

Substituting this expression and equation (39) into $H\left(\theta_{2}, e_{2}\right)$, i.e. in $\alpha^{\prime}\left(\theta_{2}\right)\left(y+d\left(e_{2}\right)+c \cdot e_{2} \cdot \theta_{2}\right)-$ $c\left(e_{2} \cdot \alpha\left(\theta_{2}\right)+q\right)$ leads to

$$
\begin{aligned}
H\left(\theta_{2}, e_{2}\right)= & \alpha^{\prime}\left(\theta_{2}\right)\left\{\omega_{2}-z_{2}+d\left(e_{2}\right)-\frac{v\left(\omega_{2}\right)-v\left(z_{2}-d\left(e_{2}\right)\right)}{\eta}\right. \\
& \left.-\frac{\psi_{2}}{\eta\left(1-u_{2}\right)} \cdot v^{\prime}\left(z_{2}-d\left(e_{2}\right)\right) \cdot d^{\prime}\left(e_{2}\right) \cdot\left(e_{2} \cdot \alpha\left(\theta_{2}\right)+q\right)\right\}
\end{aligned}
$$

Taking (30) into account, this expression can be rewritten as:

$$
\begin{aligned}
H\left(\theta_{2}, e_{2}\right)=\alpha^{\prime}\left(\theta_{2}\right) \quad & \left\{\omega_{2}-z_{2}+d\left(e_{2}\right)-\frac{v\left(\omega_{2}\right)-v\left(z_{2}-d\left(e_{2}\right)\right)}{\eta}\right. \\
& \left.-\frac{\psi_{2} \cdot \alpha\left(\theta_{2}\right)}{\eta\left(1-u_{2}\right)}\left[v\left(\omega_{2}\right)-v\left(z_{2}-d\left(e_{2}\right)\right)\right]\right\}
\end{aligned}
$$

From first-order condition (31)

$$
\frac{\psi_{2} \cdot \alpha\left(\theta_{2}\right)}{\eta\left(1-u_{2}\right)}=\frac{1}{v^{\prime}\left(\omega_{2}\right)}-\frac{1}{\eta}
$$

Therefore

$$
H\left(\theta_{2}, e_{2}\right)=\alpha^{\prime}\left(\theta_{2}\right)\left\{\omega_{2}-z_{2}+d\left(e_{2}\right)-\frac{v\left(\omega_{2}\right)-v\left(z_{2}-d\left(e_{2}\right)\right)}{v^{\prime}\left(\omega_{2}\right)}\right\}
$$

Finally, concavity of function $v($.$) implies that:$

$0<v^{\prime}\left(\omega_{2}\right) \cdot\left(\omega_{2}-z_{2}+d\left(e_{2}\right)\right)<v\left(\omega_{2}\right)-v\left(z_{2}-d\left(e_{2}\right)\right)<v^{\prime}\left(z_{2}-d\left(e_{2}\right)\right) \cdot\left(\omega_{2}-z_{2}+d\left(e_{2}\right)\right)$

Therefore, function $H$ evaluated at the second-best optimum $\left(\theta_{2}, e_{2}\right)$ is always negative. This implies that $\theta_{2}>\theta_{1}$. 


\section{Appendix 6 : The second-best optimum with risk-neutral workers}

In this appendix, we show that the paper of Hosios (1990) can be seen as a particular case of our model. To do so, we check that the decentralized equilibrium is the second-best optimum when search effort is unobservable and workers are risk neutral with $v(x)=\eta \cdot x$. We consider a laissez-faire equilibrium with $T=T_{m}=z=0$ and we assume the socalled Hosios condition is fulfilled $\gamma=-\frac{\theta \cdot m^{\prime}(\theta)}{m(\theta)}$. The proof consists in showing that the decentralized equilibrium verifies $F(\theta, e)=H(\theta, e)=0$. that:

Assuming $r=0$ in expressions (11) and (12) measured in steady state, it is easily seen

$$
\frac{V-V^{u}}{v^{\prime}(w-T)}=\frac{V-V^{u}}{v^{\prime}(z-d(e))}=\frac{w+d(e)}{q+e \cdot \alpha(\theta)}
$$

Substituting this expression in $W S(\theta, w, e)=0$ (adapted to take the above assumptions into account), one gets:

$$
\frac{w+d(e)}{q+e \cdot \alpha(\theta)}=\frac{\gamma}{1-\gamma} \cdot \frac{c}{m(\theta)}
$$

The optimal search effort level still verifies $S(\theta, w, e)=0$, which can now be rewritten as:

$$
\frac{w+d(e)}{q+e \cdot \alpha(\theta)}=\frac{d^{\prime}(e) \cdot v^{\prime}(z-d(e))}{\alpha(\theta)}
$$

Equating the left-hand sides of the two last equalities leads to:

$$
\theta=\frac{d^{\prime}(e)}{c} \frac{1-\gamma}{\gamma}
$$

which can be rewritten as:

$$
\frac{c \cdot \theta}{1-\gamma}=c \cdot \theta+d^{\prime}(e)
$$

Substituting the Hosios condition, one finally has

$$
\frac{c}{\alpha^{\prime}(\theta)}=\frac{c \cdot \theta+d^{\prime}(e)}{\alpha(\theta)}
$$

which is exactly $F(\theta, e)=0$.

Adding $d(e)$ on both sides of equality (10) leads to $w+d(e)=y+d(e)-\frac{c \cdot q}{m(\theta)}$. Combining this equality and equation (41) yields after some manipulation:

$$
\frac{y+d(e)+e \cdot c \cdot \theta}{q+e \cdot \alpha(\theta)}=\frac{1}{1-\gamma} \cdot \frac{c}{m(\theta)}
$$

Finally, replacing $\gamma$ by the Hosios condition, one ends with $H(\theta, e)=0$.

The message is exactly the main one of Hosios (1990). If redistribution (insurance) is not an issue, i.e. with marginal utilities of all agents equal and constant $\left(\eta=v^{\prime}().\right)$, the decentralized equilibrium under laissez faire is a social optimum provided that the bargaining power of the worker verifies the so-called Hosios condition $\gamma=-\theta m^{\prime}(\theta) / m(\theta)$. This property has been shown under the assumption that search effort is unobservable. One should also note that, in this case $z_{2}=\chi_{2}=T_{2}=0$. Hence, this laissez faire optimum is the only available with non negative unemployment benefits and profits. 